\title{
Maternal supplementation with corn oil associated or not with di-n-butyl phthalate increases circulating estradiol levels of gerbil offspring and impairs sperm reserve
}

\author{
Ana Carolina Negrin ${ }^{\mathrm{a}}$, Mariana Marcielo de Jesus ${ }^{\mathrm{a}}$, Caroline Maria Christante ${ }^{\mathrm{a}}$, \\ Danilo Grünig Humberto da Silva ${ }^{\mathrm{c}}$, Sebastião Roberto Taboga ${ }^{\mathrm{a}, \mathrm{b}}$, Maria Etelvina Pinto-Fochi ${ }^{\mathrm{b}, \mathrm{d}}$, \\ Rejane Maira Góes ${ }^{\mathrm{a}, \mathrm{b}, *}$ \\ ${ }^{a}$ Department of Functional and Structural Biology, Institute of Biology, University of Campinas - UNICAMP, Campinas, SP, Brazil \\ ${ }^{\mathrm{b}}$ Department of Biology, Institute of Biosciences, Humanities and Exact Sciences, São Paulo State University - UNESP, São José do Rio Preto, SP, Brazil \\ ${ }^{\mathrm{c}}$ Department of Chemistry and Environmental Sciences, Institute of Biosciences, Humanities and Exact Sciences, São Paulo State University - UNESP, São José do Rio \\ Preto, SP, Brazil \\ ${ }^{\mathrm{d}}$ Faculdade de Medicina, União das Faculdades dos Grandes Lagos - UNILAGO, São José do Rio Preto, SP, Brazil
}

\section{A R T I C L E I N F O}

\section{Keywords:}

Di- $n$-butyl phthalate

Corn oil

Lipid metabolism

Sperm reserve

Sperm motility

\begin{abstract}
A B S T R A C T
This study evaluated the consequences of gestational exposure to di- $n$-butyl phthalate (DBP) for testicular steroidogenesis and sperm parameters of the adult gerbil and the interference of corn oil (co), a vehicle widely used for administration of liposoluble agents, on DBP effects. Pregnant gerbils received no treatment or were treated from gestational day 8 to 23 via gavage with $0.1 \mathrm{~mL} /$ day of $c o$ only or containing DBP (100 mg/kg/day). Maternal co intake enhanced serum estradiol levels and testicular content of ER $\alpha$, and reduced sperm reserve of adult offspring. Gestational DBP exposure caused dyslipidemia, increased serum and intratesticular estradiol levels and reduced sperm reserve and motility. Thus, maternal co supplementation alters circulating estradiol and impairs sperm quantity and quality of offspring. Gestational DBP exposure alters lipid metabolism and testicular steroidogenesis and worsens the negative effects of $c o$ on the sperm reserve and motility of gerbil. Therefore, co interferes with the reproductive response to DBP.
\end{abstract}

\section{Introduction}

Endocrine disrupting chemical (EDC) exposure during critical periods of development, such as the fetal period and lactation, may lead to transient effects or permanently affect the homeostatic mechanisms of the endocrine system, causing physiological alterations in adulthood [1-5]. Phthalate esters are a class of EDC of growing interest for the scientific community. Phthalates are chemicals used as plasticizers in several types of plastics, mainly PVC (polyvinyl chloride) [6], being found in cosmetics, children's toys, food products and hospital supplies [7]. EDC forms non-covalent bindings with the polymers with which they are mixed [8], so, at high temperatures, they can be released into food, beverage, and other products with which they come into contact $[8,9]$.

Certain phthalates, particularly di- $n$-butyl phthalate (DBP), have been shown to interfere with the development of the male reproductive tract of the offspring when administered to pregnant rats [7,10-12]. Mylchreest et al. [7] demonstrated that rats exposed to DBP (0.5 to $500 \mathrm{mg} / \mathrm{kg} /$ day) during late gestation showed dose-dependent alterations in reproductive development, causing reduction in anogenital distance, increase in nipple number, reduction in epididimal weight, besides malformations in the testis and epididymis, and hypospadias at the highest doses. In addition, gestational exposure to DBP can reduce male fertility by decreasing testicular and epididimal sperm counts

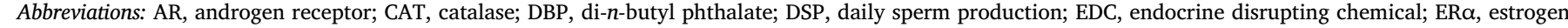

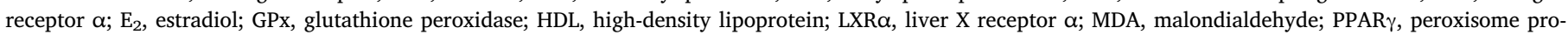
liferator-activated receptor $\gamma$; SOD, superoxide dismutase; T, testosterone; TBARS, thiobarbituric acid reactive substance; TNF $\alpha$, tumor necrosis factor $\alpha$

* Corresponding author at: Department of Biology, Institute of Biosciences, Humanities and Exact Sciences, São Paulo State University (UNESP), Rua Cristóvão Colombo, 2265, CEP 15054-000, São José do Rio Preto, SP, Brazil.

E-mail addresses: acnegrin@gmail.com (A.C. Negrin), marianamarcielo@gmail.com (M.M. de Jesus), cachristante@hotmail.com (C.M. Christante), dangrunig@gmail.com (D.G.H. da Silva), taboga@ibilce.unesp.br (S.R. Taboga), mep.fochi@yahoo.com.br (M.E. Pinto-Fochi), remagoes@ibilce.unesp.br (R.M. Góes).
} 
$[13,14]$.

Another consequence of phthalate toxicity is a reduction in testosterone synthesis during the fetal period and, sometimes, in adult life $[10,15,16]$. According to Giribabu et al. [16], rats exposed to 100 and $500 \mathrm{mg} / \mathrm{kg}$ /day of DBP during gestation present a reduction in serum testosterone levels due to an alteration in steroidogenic enzyme expression $3 \beta$-HSD and $17 \beta-H S D$. This reduction was also accompanied by impaired fertility, since the animals had decreased sperm count and motility [16]. Due to these results, the authors classify DBP and other phthalates as anti-androgenic compounds $[10,17]$. At the same time, other studies have demonstrated the estrogenic activity of phthalates, which are capable of binding to estrogen receptors (ER) $[18,19]$. Despite the anti-androgenic classification of phthalates, in utero exposure of rats to $100 \mathrm{mg} / \mathrm{kg} /$ day of DBP from gestational day 12 to postnatal day 21 altered neither testosterone levels in adult rats nor sperm counts in the testis and epididymis, sperm morphology and motility [12].

The vast majority of experimental studies focusing on the action of phthalates on reproductive organs have been performed on classical rodents such as the mouse [16,20-22] and the rat [7,10-17]. It is therefore relevant to expand our knowledge of the reproductive effects of phthalates on other rodents, such as the Mongolian gerbil. Mongolian gerbils were introduced into the Americas as a new experimental proposal in the 1950s [23] and since then they have been increasingly used in different areas of biomedical research. In our own laboratory, the gerbil has been chosen as a very useful rodent for evaluation of the prostate response, particularly because of the fact that the high frequency of the prostatic gland in the females, in comparison with other classical rodents, makes it possible to compare the prostatic response between the sexes. We therefore examined the response of the prostatic gland of the gerbil to different agents such as hormones, endocrine disruptors and dietary components [24-28]. However, the testicular response of the gerbil to phthalates is largely unknown. Experimental and epidemiological studies indicate that a variety of EDCs, including phthalates, inappropriately regulate lipid metabolism, promoting adipogenesis and obesity [29,30]. Evidence has shown that the lipid metabolism of Mongolian gerbil in response to dietary lipid components is more similar to that of the human than that of other rodents, such as the rat [31]. Thus, the gerbil may be considered to be a more suitable model for the evaluation of agents that may affect the lipid metabolism in terms of comparison with the human species.

Most of the studies found in the literature make use of corn oil as the diluent vehicle of the liposoluble compounds to be tested, such as DBP, when administered via gavage $[4,11,16,32,33]$. Recent data obtained in our laboratory have shown that small amount of corn oil, such as that used to administration of liposoluble agents, may alter sexual steroids and reproductive physiology of the Mongolian gerbil. Corn oil can play a major role in the human diet, since it provides essential fatty acids and vitamin E, besides being a source rich in polyunsaturated fats, such as omega-6 [34] and phytosterols [35]. Then, the intake of corn oil by pregnant gerbils can potentially alter the development of the reproductive organs. Additionally, considering the composition of corn oil, it is relevant to examine whether this vehicle can interfere in the phthalate effects. Thus, the aim of the present study was to investigate whether gestational exposure of pregnant gerbils to di-n-butyl phthalate impacts on the sperm parameters, lipid metabolism, testicular steroidogenesis and oxidative stress markers of adult male offspring. In addition, we evaluated the consequences of corn oil administration to pregnant gerbils on these parameters and the possible interference on di-n-butyl phthalate effects.

\section{Material and methods}

\subsection{Animals and experimental design}

Mongolian gerbils (Meriones unguiculatus) were maintained in the Animal Breeding Center of São Paulo State University (UNESP),
Institute of Biosciences, Humanities and Exact Sciences (IBILCE, São José do Rio Preto, Brazil) in polyethylene cages with shaving substrate, under controlled light (12-hour light/dark cycle) and temperature $\left(22 \pm 2{ }^{\circ} \mathrm{C}\right)$ conditions. Gerbils had free access to food and water. The experimental procedures were approved by the Institutional Committee for Ethics in Animal Experimentation of the Institute (093/2014 CEUA / UNESP).

In order to obtain the gerbils from different experimental groups, thirty-six families were formed using one male gerbil at 14 weeks of age and one female at 12 weeks of age. The age of the females for family formation was chosen based on the studies of Marston and Chang [36] and the age of the male was based on a study of spermatic reserve that shows that full sexual maturation only occurs after 12 weeks of age [37]. Day 0 of pregnancy was confirmed by vaginal swabs. Afterwards, the families were randomly divided into three groups according to the treatment of the pregnant females. The treatment occurred by gavage (via oral), from gestational day 8 to 23 . This period was chosen because gerbil implantation occurs on gestational day 8 and the gestation lasts from 24 to 26 days [38]. Following previous procedures adopted to minimize the distress associated to gavage in rats [39], all the female gerbils of the groups to be subjected to gavage were handled daily for two weeks prior in order to ease gavage administration. The number of pups per littermate varied between 6 and 8 and, at weaning, only one male per litter was chosen and placed in individual cages until the end of the experiment. Thus, three groups of adult male gerbils (16 week old) were used in this study ( $\mathrm{n}=12$ animals per group): Control group (C) - control animals, born from intact mothers, without any treatment; Oil group (O) - animals exposed during gestation to $0.1 \mathrm{~mL} /$ day of commercial corn oil (Cargil, Brazil); Phthalate group $(\mathrm{Ph})$ - animals exposed during gestation to $0.1 \mathrm{~mL} /$ day of corn oil containing $100 \mathrm{mg}$ / $\mathrm{kg}$ of DBP (Sigma-Aldrich, 524980, MO, USA). The dose of $100 \mathrm{mg} / \mathrm{kg} /$ day of DBP is the lowest dose at which adverse effects begin to occur in the reproductive system of male rats (LOAEL) [7].

The male gerbils were weighed and euthanized by $\mathrm{CO}_{2}$ inhalation, followed by decapitation for blood collection. Euthanasia was performed between 7:30 and 11:00 a.m. The weights of the testes and epididymis were measured, and the gonadosomatic index (GSI) was determined based on the formula [(testicular weight/body weight) $\times$ 100].

\subsection{Metabolic characterization}

The body weights of offspring at weaning (5weeks old) and in adulthood (16 weeks old) were determined and the adiposity index was estimated by the formula [(sum of epididymal, retroperitoneal and visceral fat/body weight) $\times 100]$, according to Taylor and Phillips [40]. The glucose concentrations were determined at the end of the experiment with the Accu-Chek Active monitor (Roche Diagnostics, Switzerland), from blood drops taken from the cervical region.

The lipid profile was evaluated by colorimetric-enzymatic tests to assess total cholesterol, high-density lipoprotein (HDL), non-HDL and triglycerides levels (In vitro Diagnóstica Ltda, MG, Brazil). The test was realized in serum samples, after blood centrifugation (1200 g, $20 \mathrm{~min}$ ). Each sample was evaluated in triplicate in a Thermo Scientific Evolution 300 UV-vis spectrophotometer (Thermo Fisher Scientific, MA, USA). The triglycerides/HDL ratio was calculated as a predictor of insulin resistance, as proposed by Fan et al. [41].

\subsection{Sperm counts}

Spermatids resistant to homogenization (stages 13, 14 and 15 of spermiogenesis) [42] and spermatozoa present in the caput/corpus and cauda of the epididymis were estimated as described by Robb et al. [43], with modifications according to Fernandes et al. [44]. After homogenization of the testes and epididymis regions in $0.9 \% \mathrm{NaCl}$ with $0.5 \%$ TritonX100, testicular and epididimal samples were diluted $10 \times$ 
and $20 \times$, respectively. Counts were performed in Neubauer chambers (Laboropitk Ltd, UK). To determine the daily sperm production (DSP), the number of spermatids per testis was divided by 5.81 , which is the number of days in which mature spermatids resistant to homogenization are present in the seminiferous epithelium [42]. DSP per gram was calculated in order to determine the efficiency of the spermatogenic process $[45,46]$. Sperm reserve was obtained by the number of spermatozoa in the cauda of the epididymis multiplied by 2 . The sperm transit time through the caput/corpus and cauda of the epididymis was obtained by dividing the number of spermatozoa present in each of these regions by the DSP [47].

\subsection{Sperm motility}

Estimation of sperm motility was performed immediately after euthanasia, using the cauda of the epididymis. Sperm was obtained through perforations made with the aid of a needle in $1.0 \mathrm{~mL}$ of modified HTF medium (Human Tubal Fluid, Irvine Scientific, CA, USA) at $34^{\circ} \mathrm{C}$ A Makler counting chamber (Sefi-Medical Instruments, Israel) warmed to $34^{\circ} \mathrm{C}$ was loaded with $10 \mu \mathrm{L}$ of sperm solution. The evaluation of sperm motility was assessed by visual estimation (100 spermatozoa per animal, in duplicate) under a phase-contrast microscope (Olympus BX60, Olympus Corporation, Japan) at $200 \times$ magnification. Spermatozoa were classified as motile with progressive movement, motile without progressive movement and immotile [48].

\subsection{Histological alterations and apoptosis index}

The testes were removed and fixed in Bouin's fluid for $12 \mathrm{~h}$. Fragments were washed several times in 70\% alcohol, processed for inclusion in Paraplast (Merck, Germany) in a TP1020 processor (Leica Microsystems Brazil, China) and used for general histological analysis.

Histological sections stained with Hematoxylin-Eosin (HE) were used for the general histological analysis. The entire histological section from each testis fragment was examined, and the number of seminiferous tubules affected by some type of histopathological alteration was counted and expressed as a percentage of the total number of seminiferous tubules of the section. Two histological sections of two distinct fragments per animal were evaluated in five animals per group.

Apoptotic cells were detected using the DNA fragmentation assay associated with cell death, based on the TUNEL reaction, according to the kit instructions (ApopTag Plus in situ, Apoptosis Detection Kit, Millipore, 57101, CA, USA). Briefly, after digestion with proteinase K (\#JA 1477, Calbiochem, Germany), the histological sections were submitted to procedures designed to inactivate endogenous peroxidase ( $3 \% \mathrm{H}_{2} \mathrm{O}_{2}$ in PBS, $5 \mathrm{~min}$ ), and then incubated with the enzyme deoxynucleotidyl terminal transferase (TdT) for $40 \mathrm{~min}$ at $37^{\circ} \mathrm{C}$. At the end of the reaction, the sections were incubated with peroxidase, revealed with diaminobenzidine (DAB) and counterstained with Harris' Hematoxylin. The estimation of the apoptosis index was determined by the ratio of the number of apoptotic cells in the entire histological section and the corresponding section area. This analysis was performed in five histological sections of five distinct animals per group.

The images were obtained with a Pike F-505C VC50 camera (Allied Vision Technologies, Germany) attached to an Olympus VS10 Virtual Microscope Slide Scanning System (Olympus Corporation, Japan).

\subsection{Protein expression in testicular samples}

The protein content of the peroxisome proliferator-activated receptor $\gamma(\operatorname{PPAR} \gamma)$, liver X receptor $\alpha(\mathrm{LXR} \alpha)$, androgen receptor (AR) and estrogen receptor $\alpha(E R \alpha)$ were quantified in testis samples by Western blotting. Total extracts were obtained from $100 \mathrm{mg}$ of tissue fragments, homogenized in RIPA buffer (Sigma, MO, USA) with a cocktail of protease inhibitors (Sigma, MO, USA) and Triton X100. The homogenate was centrifuged at $18,000 \mathrm{~g}$ for $20 \mathrm{~min}$ at $4{ }^{\circ} \mathrm{C}$ and the
Table 1

Description of the antibodies and protocols used in the immunoblotting.

\begin{tabular}{|c|c|c|c|c|}
\hline \multicolumn{2}{|c|}{ Primary antibody } & \multirow{2}{*}{$\begin{array}{l}\text { Dilution } \\
1: 400\end{array}$} & \multirow{2}{*}{$\begin{array}{l}\begin{array}{l}\text { Secundary } \\
\text { antibody }\end{array} \\
\text { Anti-rabbit }\end{array}$} & \multirow{2}{*}{$\begin{array}{l}\text { Dilution } \\
1: 4,000\end{array}$} \\
\hline Anti-PPAR $\gamma$ & $\begin{array}{l}\text { Abcam (MA, USA) - } \\
209350\end{array}$ & & & \\
\hline Anti-LXR $\alpha$ & $\begin{array}{l}\text { Abcam (MA, USA) - } \\
106464\end{array}$ & $1: 200$ & Anti-rabbit & $1: 10,000$ \\
\hline Anti-AR & $\begin{array}{l}\text { Santa Cruz Biotechnology } \\
\text { (CA, USA) - sc- } 816\end{array}$ & $1: 300$ & Anti-rabbit & $1: 3,000$ \\
\hline Anti-ER $\alpha$ & $\begin{array}{l}\text { Santa Cruz Biotechnology } \\
\text { (CA, USA) - sc- } 8005\end{array}$ & $1: 200$ & Anti-mouse & $1: 7,000$ \\
\hline Anti- $\beta$-actin & $\begin{array}{l}\text { Santa Cruz Biotechnology } \\
\text { (CA, USA) - sc- } 47778\end{array}$ & $1: 1000$ & Anti-mouse & $1: 10,000$ \\
\hline
\end{tabular}

supernatant was stored at $-80^{\circ} \mathrm{C}$. The protein dosage was quantified by the Bradford method [49] and $30 \mu \mathrm{g}$ of proteins were subjected to SDSPAGE and transferred to nitrocellulose membrane (GE Healthcare, Italy). Blots were blocked with $5 \%$ nonfat dry milk in TBST buffer (10 mM Tris-HCl, pH 7.4, $150 \mathrm{mM} \mathrm{NaCl}$ and $0.2 \%$ Tween-20) for $30 \mathrm{~min}$ at room temperature, followed by overnight incubation at $4{ }^{\circ} \mathrm{C}$ with primary antibodies, according to Table 1 . Thereafter, the membranes were washed in TBST for three 10-min cycles, incubated for $1 \mathrm{~h}$ with a specific secondary horseradish peroxidase-conjugate antibody (Table 1) at room temperature, and washed in TBST for three $10 \mathrm{~min}$ cycles once more. Protein expression was normalized to the $\beta$-actin values (Table 1). Antibody detection was revealed using the ECL chemiluminescent detection kit (GE Healthcare, Italy). The membranes were revealed in G: BOX Chemi XRQ photodocumentator (Syngene Synoptics Ltd, UK) and the band densities were analyzed in a densitometry program - Image J 1.34 (Wayne Rasband, Research Services Banch, National Institute of Mental Health, MD, USA).

\subsection{Testicular TNF $\alpha$ concentration}

Testicular fragments were homogenized in lysis buffer $(50 \mathrm{mM}$ Tris$\mathrm{HCl}$ and $150 \mathrm{mM} \mathrm{NaCl}$ ) with a Protease Inhibitor Cocktail Set I (Cat. No. 539131, Calbiochem-Merck, Germany). The homogenate was centrifuged at $18,000 \mathrm{~g}$ for $10 \mathrm{~min}$ at $4{ }^{\circ} \mathrm{C}$. Supernatant was used for total protein dosage [49] and determining of the proinflammatory cytokine tumor necrosis factor $\alpha$ (TNF $\alpha)$. TNF $\alpha$ was quantified by capture/ sandwich ELISA using specific commercial kits from R\&D System (DY510, MN, USA), and the results were normalized by concentration of total proteins.

\subsection{Hormone levels}

After euthanasia, blood samples were centrifuged (1200 g, $20 \mathrm{~min}$ ) and the serum obtained was frozen at $-80^{\circ} \mathrm{C}$ for hormone analyses. Serum testosterone $(\mathrm{T})$ and estradiol $\left(\mathrm{E}_{2}\right)$ levels were analyzed in duplicate by capture/sandwich ELISA using specific commercial kits, according to the instructions of the manufacturer (Testosterone EIA Kit, No. 582701, and Estradiol EIA Kit, No. 582251, Cayman Chemical Company, MI, USA).

Intratesticular hormone concentration was performed after the testes were processed for extraction of steroids, according to PintoFochi et al. [50]. Testis fragments were homogenized in PBS and incubated in a tube with diethyl ether for 10 min initially at room temperature and subsequently on dry ice. The supernatants were removed and transferred to another tube and stored until complete evaporation of the diethyl ether. The material was suspended in PBS and stored at $-80^{\circ} \mathrm{C}$ until hormone determining. $\mathrm{T}$ and $\mathrm{E}_{2}$ concentrations were also analyzed in duplicate using ELISA capture/sandwich and specific commercial kits (Testosterone Test System, code 3775-300, Monobind Inc., CA, USA, and Estradiol EIA Kit, No. 582251, Cayman Chemical Company, MI, USA). 
The readings were performed in a SpectraMax Plus 384 microplate reader (Molecular Devices, CA, USA).

\subsection{Activity of antioxidant enzymes}

Testicular and epididimal fragments were weighed and stored at $-80^{\circ} \mathrm{C}$. Then, the fragments were homogenized in 1: $4 \mathrm{vol}$ of Tris- $\mathrm{HCl}$ buffer ( $0.2 \mathrm{mM}, \mathrm{pH} 7.5$ ) with $1 \mathrm{mM}$ EDTA, $1 \mathrm{mM}$ DTT, $0.5 \mathrm{M}$ sacarose and $0.15 \mathrm{M} \mathrm{KCl}$, and centrifuged at $10,000 \mathrm{~g}$ for $20 \mathrm{~min}$ at $3{ }^{\circ} \mathrm{C}$. The supernatant was centrifuged once more at $50,000 \mathrm{~g}$ for $60 \mathrm{~min}$ at $1{ }^{\circ} \mathrm{C}$. The new supernatant fraction was collected, aliquoted and used to determine the enzyme activities of Catalase (CAT) [51], Glutathione peroxidase (GPx) [52] and Superoxide dismutase (SOD) by kit, according to the instructions of the manufacturer (Sigma-Aldrich, No. 19160, MO, USA). The total protein content was determined by the Bradford method [49]. Analyses of CAT and GPx were performed in a Thermo Scientific Evolution 300 UV-vis spectrophotometer (Thermo Fisher Scientific, MA, USA). SOD activity was determined with a Victor TM X3 microplate reader (Perkin ElmerR, MA, USA). The aforementioned analyses were also applied to the hemolysate obtained through blood samples collected, immediately after euthanasia, in polyethylene tubes containing heparin.

\subsection{Oxidized biomolecule levels}

As oxidation marker, the levels of colored adducts produced by the reaction of oxidized biomolecules with thiobarbituric acid (TBA) [53] were measured in plasma samples and fragments of testis and epididymis. Plasma samples were obtained after centrifugation of the hemolysate $(850 \mathrm{~g}, 10 \mathrm{~min})$. Testicular and epididimal fragments were weighed and homogenized in 1:3 vol of Tris- $\mathrm{HCl}$ buffer $(0.1 \mathrm{M}, \mathrm{pH} 8)$. Following the addition of $300 \mu \mathrm{L}$ TBA, the homogenate was incubated at $90^{\circ} \mathrm{C}$ for $40 \mathrm{~min}$ and, subsequently, incubated on ice to stop the reaction. Afterwards, $600 \mu \mathrm{L}$ n-butanol was added to the homogenate, which was centrifuged at $2,500 \mathrm{~g}$ for $5 \mathrm{~min}$. The supernatant was collected and used for oxidized biomolecule determination. Products were detected by spectrophotometry (SpectraMax Plus 384 microplate reader, Molecular Devices, CA, USA), according to Uchiyama and Mihara [54].

\subsection{Statistical analysis}

Statistical analyses were performed by Statistica 8.0 software (Statsoft. Inc., OK, USA), while the graphics were done using GraphPad Prisma 5.01for Windows (GraphPad Software, CA, USA). First, the data were checked for normality using the Kolmogorov-Smirnov test. Parametric data were analyzed by one-way ANOVA followed by Tukey's test. For non-parametric data, the Kruskal-Wallis test followed by Dunn's test was used. Differences were considered statistically significant when $\mathrm{p}<0.05$.

\section{Results}

\subsection{Effects on metabolic parameters}

The intake by pregnant mothers of corn oil alone or containing DBP did not affect the body weight and the adiposity index of the offspring when compared to the offspring of untreated mothers (Table 2). Neither the glucose levels (C: $81.2 \pm 3.5$; O: $78.6 \pm 2.9$; Ph: $84.0 \pm 3.0 \mathrm{mg}$ / $\mathrm{dL} ; \mathrm{p}=0.49$ ) nor the triglyceride/HDL ratio (C: $3.3 \pm 0.5 ; \mathrm{O}$ : $3.2 \pm 0.5$; Ph: $4.1 \pm 0.6 ; \mathrm{p}=0.59$ ) were affected. Regarding the lipid profile, the $\mathrm{O}$ group showed an increase non-HDL cholesterol serum levels in relation to the $C$ group $(\sim 37 \%$; $p=0.53$ ) (Fig. 1$)$. When the $\mathrm{Ph}$ and $\mathrm{C}$ groups were compared there was an increase in serum levels of total cholesterol $(\sim 43 \%)$, non-HDL cholesterol $(\sim 66 \%)$ and triglycerides ( $\sim 90 \%)$ (Fig. 1).
Table 2

Biometric data of the animals from the Control (C), Oil (O) and Phthalate (Ph) groups.

\begin{tabular}{|c|c|c|c|}
\hline \multirow[t]{2}{*}{$\mathrm{n}=12$ per group } & \multicolumn{3}{|c|}{ Experimental groups } \\
\hline & $\mathrm{C}$ & $\mathrm{O}$ & $\mathrm{Ph}$ \\
\hline Body weight at $5^{\text {th }}$ weeks old $(\mathrm{g})^{\mathrm{a}}$ & $27.8 \pm 0.7$ & $24.0 \pm 1.4$ & $24.6 \pm 1.1$ \\
\hline Body weight at $16^{\text {th }}$ weeks old $(\mathrm{g})^{\mathrm{b}}$ & $70.6 \pm 1.0$ & $67.6 \pm 1.1$ & $68.8 \pm 1.5$ \\
\hline Adiposity index $(\%)^{\mathrm{a}}$ & $2.89 \pm 0.2$ & $2.48 \pm 0.2$ & $2.81 \pm 0.2$ \\
\hline Testicular weight $(\mathrm{mg})^{\mathrm{a}}$ & $537.5 \pm 12.1$ & $513.9 \pm 8.0$ & $524.8 \pm 9.7$ \\
\hline Gonadosomatic index $(\%)^{\mathrm{a}}$ & $0.76 \pm 0.01$ & $0.76 \pm 0.01$ & $0.76 \pm 0.01$ \\
\hline Epididimal weight $(\mathrm{mg})^{\mathrm{b}}$ & $199.2 \pm 4.1$ & $186.0 \pm 4.0$ & $194.2 \pm 4.5$ \\
\hline
\end{tabular}

Values expressed as median \pm SEM.

a ANOVA followed by Tukey's test.

b Kruskal-Wallis test followed by Dunn's test.

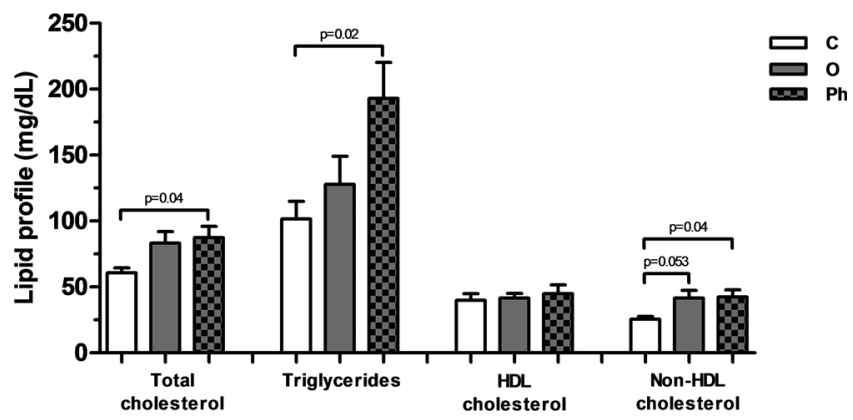

Fig. 1. Lipid profile of the gerbils from the Control (C), Oil (O) and Phthalate $(\mathrm{Ph})$ groups. $\mathrm{n}=10$ animals per group. Values are expressed as mean $\pm \mathrm{SEM}$. Values $\mathrm{p}<0.05$ were considered significant (ANOVA test followed by Tukey's test).

\subsection{Effects on sperm parameters}

The gerbils of the $\mathrm{O}$ and $\mathrm{Ph}$ groups did not show any change in testicular and epididimal weights nor in GSI in relation to the gerbils from the $\mathrm{C}$ group (Table 2). There were no alterations in the testicular sperm counts and DSP of the $\mathrm{O}$ and $\mathrm{Ph}$ groups in relation to those in the $\mathrm{C}$ group (Table 3 ). The sperm reserve was reduced by $\sim 21 \%$ in the $\mathrm{O}$ group and $\sim 68 \%$ in the $\mathrm{Ph}$ group in relation to the control animals, since the number of spermatozoa in the caput/corpus of the epididymis was reduced in the $\mathrm{Ph}$ group and the number in the cauda of the epididymis was decreased in the $\mathrm{O}$ and $\mathrm{Ph}$ groups (Table 3 ). The sperm transit time through the epididymis was not altered in the $\mathrm{Ph}$ group, however, it decreased by about $16 \%$ in the $\mathrm{O}$ group when compared to the $\mathrm{C}$ group (Table 3 ).

DBP exposure during gestation had a negative effect on sperm motility, with a reduction in the rate of spermatozoa with progressive movement and an increase in the rate of spermatozoa without progressive movement and immotile spermatozoa in relation to the animals of the $\mathrm{C}$ and $\mathrm{O}$ groups (Fig. 2). In the $\mathrm{O}$ group there was also an increase in the rate of spermatozoa without progressive movement when compared to the $\mathrm{C}$ group (Fig. 2).

\subsection{Effects on testis histology, apoptosis and expression of nuclear receptors}

Histopathological analysis did not indicate tissue lesions in the testis of the animals of both groups, except for an increase in the number of seminiferous tubules presenting premature detachment of the germinative epithelium in the $\mathrm{O}$ group in relation to the $\mathrm{C}$ group (Fig. 3). Four out of five animals evaluated per group showed premature cell detachment in both $\mathrm{O}$ and $\mathrm{Ph}$ groups (C: $0 \pm 0$; O: $1.42 \pm 0.46$; Ph: $0.72 \pm 0.38 \%$ of the total tissue section area).

The relative density of apoptotic cells in the testis did not change in 
Table 3

Testicular and epididymal sperm counts, and sperm transit time through the epididymis of gerbils from the Control (C), Oil (O) and Phthalate (Ph) groups.

\begin{tabular}{|c|c|c|c|}
\hline \multirow[t]{2}{*}{$\mathrm{n}=12$ per group } & \multicolumn{3}{|c|}{ Experimental groups } \\
\hline & $\mathrm{C}$ & $\mathrm{O}$ & $\mathrm{Ph}$ \\
\hline Sperm number in the testis $\left(\times 10^{6}\right)$ & $77.4 \pm 4.1$ & $73.3 \pm 3.7$ & $66.1 \pm 2.4$ \\
\hline Sperm number per gram of testis $\left(\times 10^{6}\right)$ & $146.0 \pm 6.8$ & $145.8 \pm 7.0$ & $130.9 \pm 4.5$ \\
\hline $\operatorname{DSP}\left(\times 10^{6}\right)$ & $13.3 \pm 0.7$ & $12.6 \pm 0.6$ & $11.4 \pm 0.3$ \\
\hline DSP per gram $\left(\times 10^{6}\right)^{\mathrm{a}}$ & $25.1 \pm 1.2$ & $25.1 \pm 1.2$ & $22.5 \pm 0.8$ \\
\hline Sperm number in the caput/corpus of the epididymis $\left(\times 10^{6}\right)$ & $13.8 \pm 0.8$ & $12.0 \pm 0.5$ & $10.1 \pm 0.5^{\mathrm{a}}$ \\
\hline Sperm number per gram of caput/corpus of the epididymis $\left(x 10^{6}\right)$ & $194.1 \pm 8.8$ & $181.4 \pm 8.9$ & $149.6 \pm 6.2^{\mathrm{a}, \mathrm{b}}$ \\
\hline Sperm number in the cauda of the epididymis $\left(\times 10^{6}\right)$ & $166.3 \pm 7.8$ & $130.6 \pm 5.9^{\mathrm{a}}$ & $130.4 \pm 6.7^{\mathrm{a}}$ \\
\hline Sperm number per gram of cauda of the epididymis $\left(\times 10^{6}\right)$ & $1266 \pm 42.2$ & $1077 \pm 36.3^{\mathrm{a}}$ & $1061 \pm 32.7^{\mathrm{a}}$ \\
\hline Sperm reserve in the epididymis $\left(\times 10^{6}\right)^{\mathrm{b}}$ & $332.6 \pm 15.6$ & $261.3 \pm 11.8^{\mathrm{a}}$ & $260.7 \pm 13.3^{\mathrm{a}}$ \\
\hline \multicolumn{4}{|l|}{ Sperm transit time in the epididymis (days) } \\
\hline Caput/corpus & $1.05 \pm 0.07$ & $0.97 \pm 0.05$ & $0.90 \pm 0.06$ \\
\hline Cauda & $12.62 \pm 0.46$ & $10.48 \pm 0.43^{\mathrm{a}}$ & $11.46 \pm 0.46$ \\
\hline Total & $13.67 \pm 1.72$ & $11.70 \pm 1.36^{\mathrm{a}}$ & $12.36 \pm 1.67$ \\
\hline
\end{tabular}

Values expressed as mean \pm SEM.

The superscripts a, b indicate statistical difference among the groups: a p $<0.05$ versus C; b p $<0.05$ versus $\mathrm{O}$ (Kruskal-Wallis test followed by Dunn's test).

a Espermatogenic efficiency.

b Value per cauda of the epididymis multiplied by 2 .

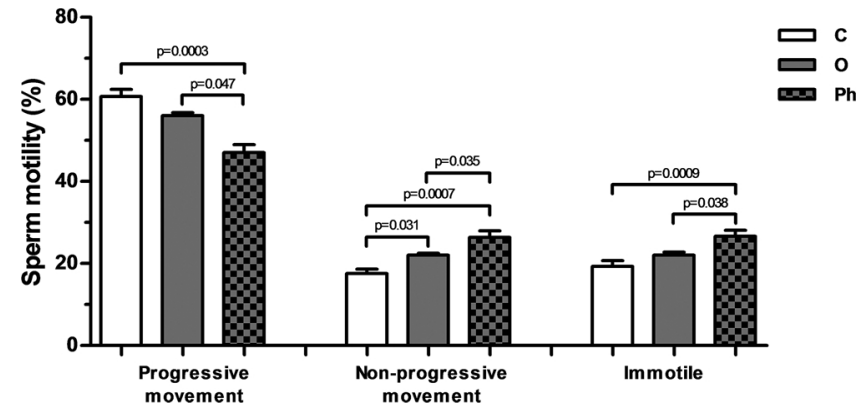

Fig. 2. Sperm motility of the animals from the Control (C), Oil (O) and Phthalate $(\mathrm{Ph})$ groups. Sperm were analyzed according to the movement type: progressive movement, non-progressive movement and immotile. $\mathrm{n}=10$ animals per group. Values are expressed as mean \pm SEM. Values $\mathrm{p}<0.05$ were considered significant (Kruskal-Wallis test followed by Dunn's test).

the $O$ group, but increased by about $48 \%$ in the animals exposed to DBP in comparison to the $\mathrm{C}$ animals (Fig. 4).

Testicular expression of the nuclear receptors PPAR $\gamma, \mathrm{LXR} \alpha$ and AR did not vary in the $\mathrm{O}$ and $\mathrm{Ph}$ groups (Fig. $5 \mathrm{~A}-\mathrm{C}$ ). On the other hand, $\mathrm{ER} \alpha$ content in the testis was approximately $78 \%$ higher in the O group when compared to the $\mathrm{C}$ group (Fig. 5D). ER $\alpha$ expression did not vary in the $\mathrm{Ph}$ group when compared with the control group (Fig. 5D).

No differences were observed in testicular concentrations of TNF $\alpha$ among the groups (C: $4.54 \pm 0.18 ; \quad$ O: $5.23 \pm 0.29 ; \quad \mathrm{Ph}$ : $\left.4.89 \pm 0.46 \times 10^{-8} \mathrm{pg} / \mathrm{mL} ; \mathrm{p}=0.34\right)$.

\subsection{Effects on sexual steroids}

No alterations were observed in serum and intratesticular $\mathrm{T}$ levels among the groups (Fig. 6A and B). When compared to the $\mathrm{C}$ group, serum levels of $\mathrm{E}_{2}$ increased by about $52 \%$ and $54 \%$ in the $\mathrm{O}$ and $\mathrm{Ph}$ groups, respectively (Fig. 6C). Intratesticular $\mathrm{E}_{2}$ levels were approximately $86 \%$ higher in the $\mathrm{Ph}$ group in relation to the $\mathrm{C}$ and $\mathrm{O}$ groups (Fig. 6D).

\subsection{Effects on oxidative stress markers}

In relation to the activity of the antioxidant enzymes, CAT and SOD activity was higher in the blood of the $\mathrm{O}$ and $\mathrm{Ph}$ animals when compared to the animals of the C group (Fig. 7A, G), while GPx activity was unchanged among the groups (Fig. 7D). In the testis, the antioxidant activity of CAT was lower in the $\mathrm{O}$ group than in the $\mathrm{C}$ group (Fig. 7B), and no changes were observed in GPx and SOD activity among the groups (Fig. 7E and H). In the epididymis, there was no change in the activity of CAT, GPx and SOD enzymes in both $\mathrm{O}$ and $\mathrm{Ph}$ groups (Fig. 7C, F and I).

Thiobarbituric acid reactive substance (TBARS) assay demonstrated that there was an increase by about $80 \%$ in plasmatic oxidized biomolecule levels of the $\mathrm{Ph}$ animals in comparison to the $\mathrm{C}$ animals (Fig. 7J). No changes were observed in the levels of testicular oxidized biomolecules among the groups (Fig. 7K). However, there was a reduction of approximately $46 \%$ in epididymal oxidized biomolecule levels in the $\mathrm{Ph}$ group compared to the $\mathrm{O}$ group (Fig. $7 \mathrm{~L}$ ).

\section{Discussion}

The present study with gerbils demonstrated that the maternal intake of a small amount of corn oil ( $100 \mu \mathrm{l} /$ day), a vehicle widely used for the dilution of liposoluble agents, led to persistent alterations in the sex steroid metabolism, causing an increase in both circulating estradiol and the content of ERa in the testis of the male offspring at adulthood and a reduction in the sperm reserve. It was also demonstrated that gestational exposure to $100 \mathrm{mg} / \mathrm{kg} /$ day of DBP in the same volume of corn oil further reduced the sperm reserve and impaired sperm motility of the adult offspring. The alterations caused by DBP were associated with perturbations in the intratesticular synthesis of estradiol and systemic alterations in the lipid metabolism.

\subsection{Effects on adiposity and the lipid metabolism}

DBP and other EDCs are known to act as obesogenic agents, promoting obesity by altering the lipid metabolism and adipogenesis process [29]. In the present study, it was verified that the animals exposed to DBP were dyslipidemic, presenting higher levels of serum triglycerides, total cholesterol and non-HDL cholesterol. Thus, gestational exposure to DBP causes dyslipidemia in gerbils in adulthood. Mice exposed in utero to the diethylstilbestrol (DES) deregulator also showed higher serum triglyceride levels, as well as leptin and interleukin 6 (IL6) at two months of age, even before they become overweight and obese [3]. These animals presented higher adiposity and obesity from the third month of life, suggesting that high levels of triglycerides, leptin and IL- 6 would be important early markers of the metabolic syndrome [3]. In comparison with mice exposed during gestation to DES [3], the data obtained here for the gerbil, after DBP exposure, also reveal alterations in total cholesterol and non-HDL cholesterol. Experimental 


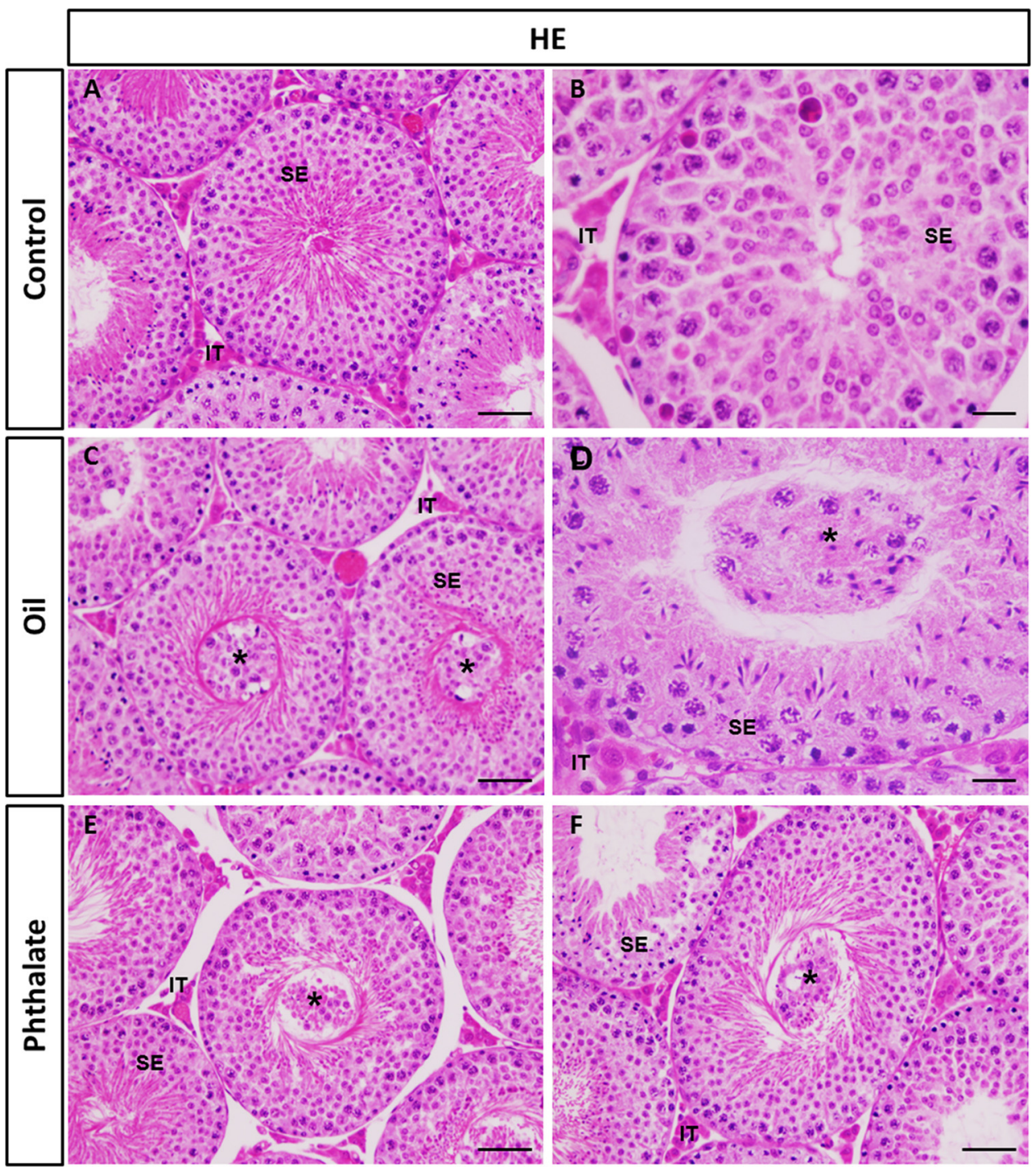

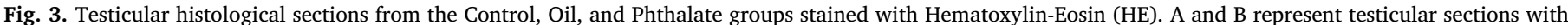

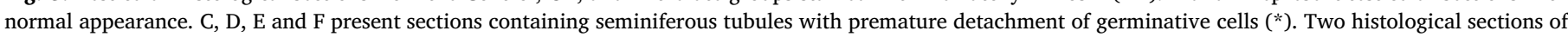

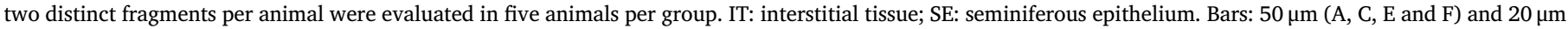
(B and D).

feeding of gerbils with a high-fat diet for two weeks showed that gerbils exhibit a higher susceptibility to hypercholesterolemia than other rodents, which is related to the stable expression of sterol regulatory element binding protein (SREBP)-2 in the liver [55]. These findings may explain the hypercholesterolemia detected in the present study for gerbils after DBP exposure and not for other rodents [3].

It should be noted that isolated exposure to corn oil also marginally altered non-HDL cholesterol levels, which were $\sim 63 \%$ higher in the $\mathrm{O}$ group than in the $C$ group $(p=0.053)$. Clinical and experimental studies have implicated this plant oil, as well as corn fiber oil, in the regulation of serum cholesterol levels of adult individuals [35,56,57]. A study by Poveda et al. [58] demonstrated that the consumption of $0.2 \mathrm{~mL} /$ day of corn oil by female Wistar rats for two weeks enhanced the serum HDL cholesterol levels. The authors suggest that the high concentration of tocopherols, a vitamin E constituent present in corn oil, may improve the lipid profile and increased HDL cholesterol levels [58]. It is known that fatty acids in the maternal circulation can be transported through the placenta and captured by the liver of the fetus, being subsequently esterified and released as triglycerides in the circulation [59]. In postnatal life, the lipid metabolism and, consequently, the profile of circulating lipids is largely determined by hepatic function
[60]. Other studies indicate that the offspring of mice fed a high-fat diet during gestation have impaired hepatic function in adulthood [61]. Our results corroborate the data of Gregorio et al. [61], indicating that, despite not affecting adiposity in early adulthood, the consumption of a small amount of corn oil during pregnancy may interfere with the lipid metabolism of the offspring in a different manner from that occur in our own consumption, increasing cholesterol levels [58]. It was not the aim of this study to evaluate the mechanisms by which corn oil and DBP impairs the lipid metabolism, which would require other analyses of the liver and adipose tissue, which were not predicted in this study. However, it is known from the literature that phthalates can act in the induction of metabolic syndrome by interfering with the signaling of LXR $\alpha, \operatorname{PPAR} \gamma$ and ER $\alpha$ [22,62-64]. Our data suggest that ingestion of the corn oil diluent vehicle interferes with the lipid metabolism, especially of cholesterol, and DBP potentiates these disorders, increasing serum triglycerides levels, demonstrating an additive or synergistic effect of the two compounds. It has been hypothesized that oils containing high levels of omega-3 polyunsaturated fatty acids, such as canola and fish oil, could counteract some of the adverse effects induced by phthalates. 


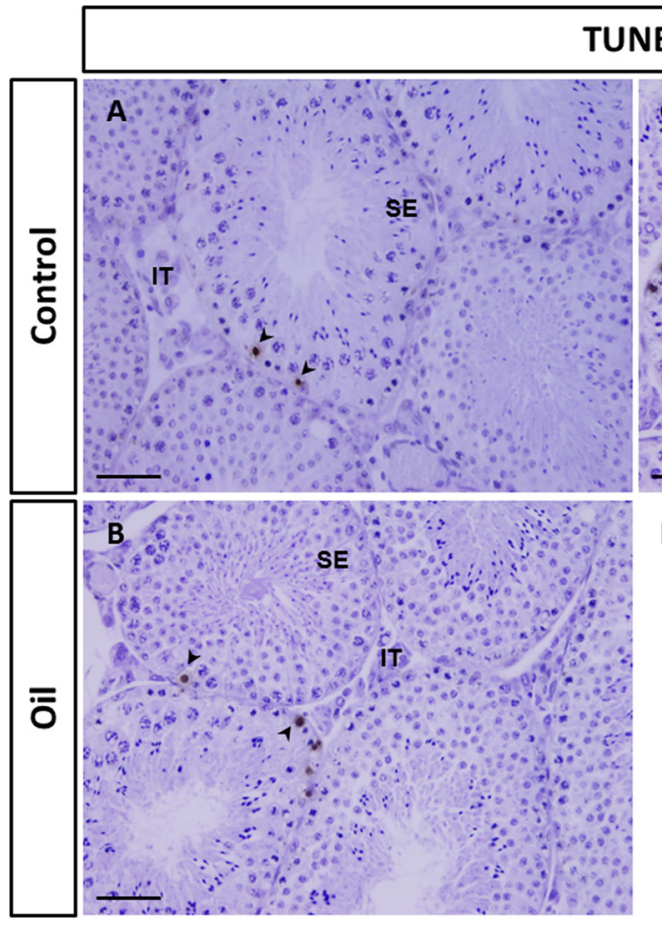

A

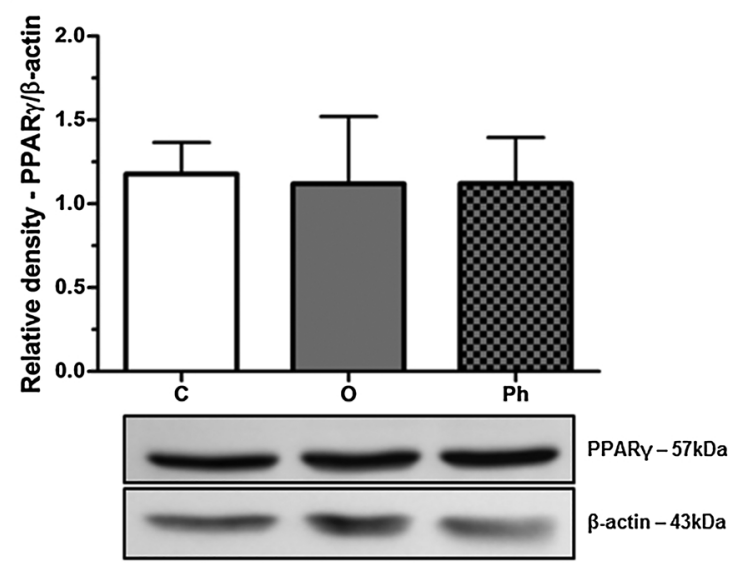

C

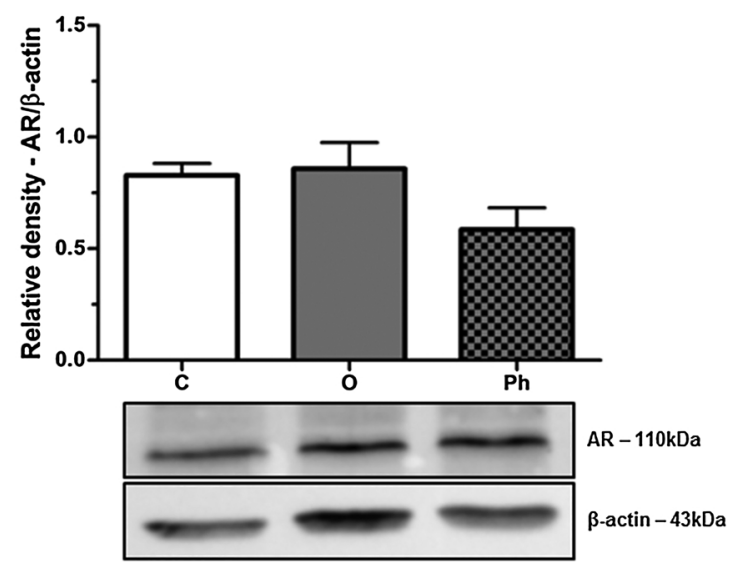

B

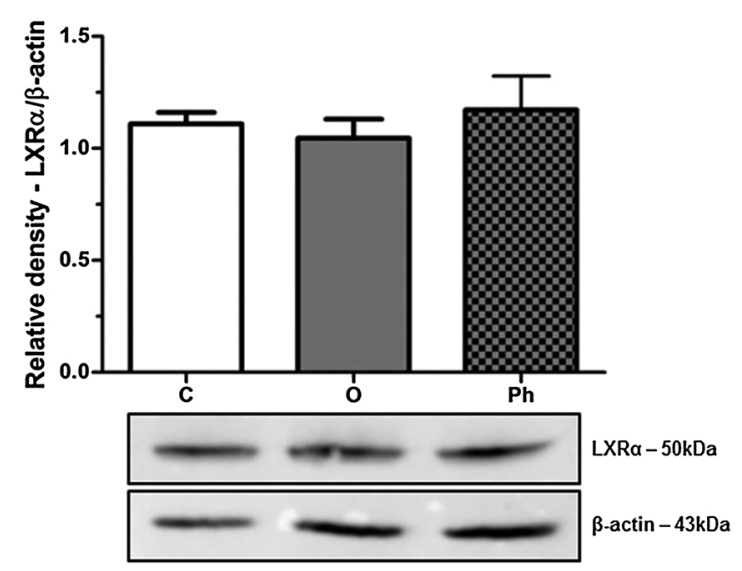

D

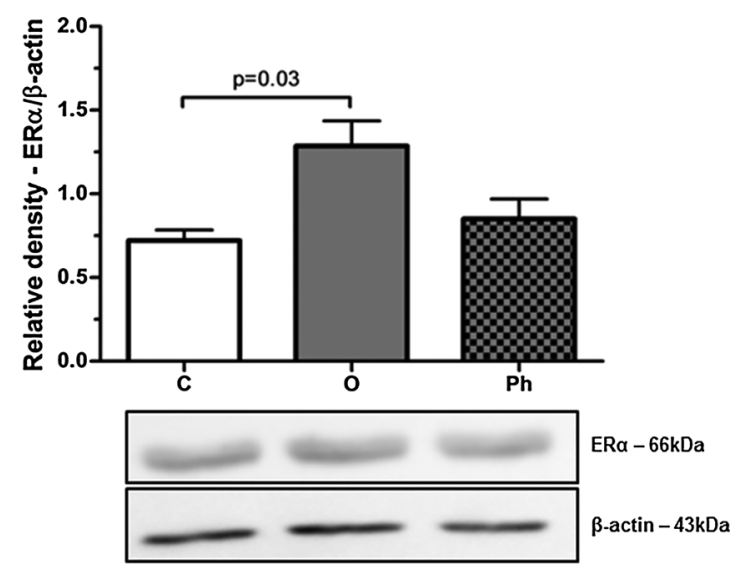

Fig. 5. Determination of the expression of the peroxisome proliferator-activated receptor $\gamma$ (PPAR $\gamma$; A), liver X receptor $\alpha$ (LXR $\alpha$; B), androgen receptor (AR; C) and estrogen receptor $\alpha(E R \alpha ; D)$ in the testis of gerbils from the Control (C), Oil (O) and Phthalate (Ph) groups, normalized by $\beta$-actin, which was used as a positive control. $n=4$ animals per group. Values are expressed as mean \pm SEM. Values $p<0.05$ were considered significant (Kruskal-Wallis test followed by Dunn's test). 
A

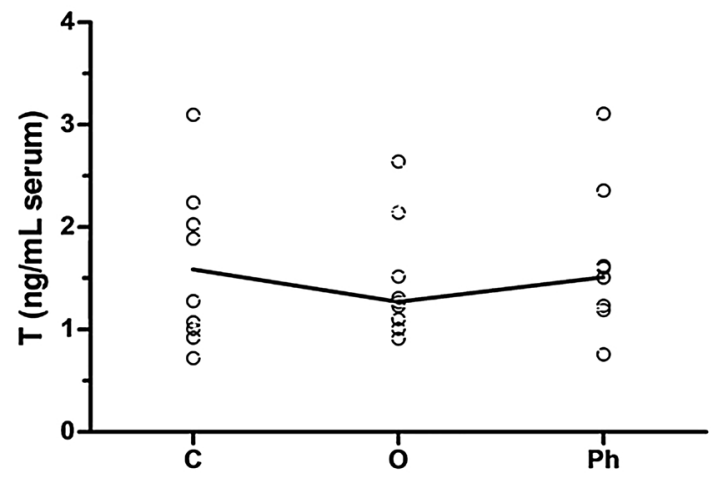

C

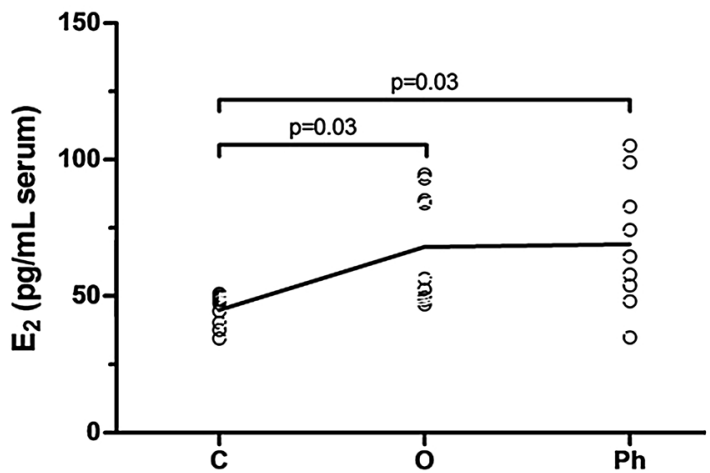

B

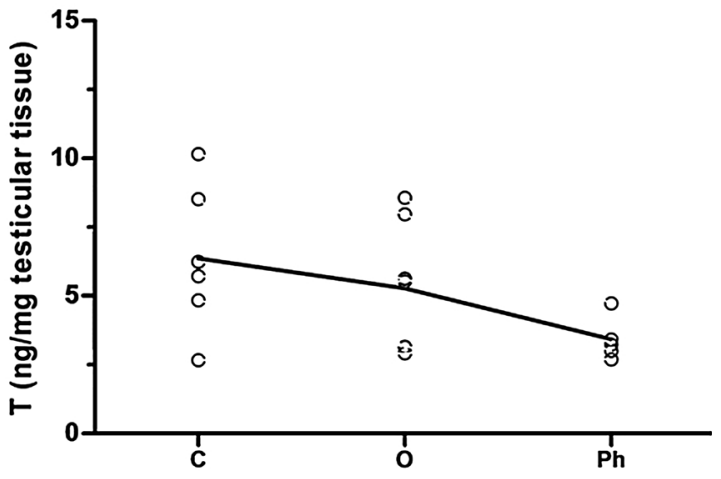

D

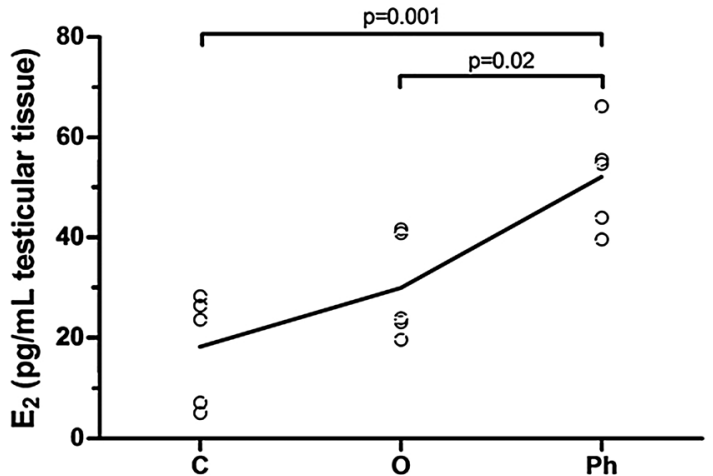

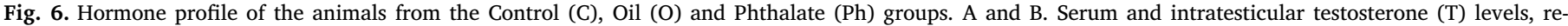

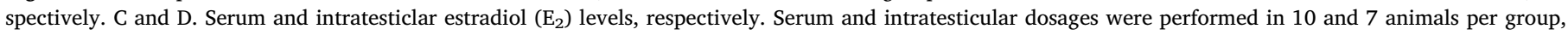

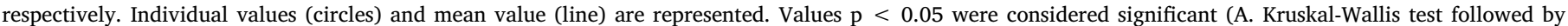
Dunn's test; B, C and D. ANOVA test followed by Tukey's test).

\subsection{Effects on sexual hormones}

Disorders caused by EDCs in critical periods of development, such as the fetal period, may be transitory or affect the homeostatic mechanisms of the endocrine system permanently [1-5]. We found that gestational exposure of gerbils to $100 \mathrm{mg} / \mathrm{kg}$ /day of DBP increases the serum and intratesticular estradiol levels. However, these changes occur without impacting the serum and intratesticular levels of testosterone. It is known that intrauterine exposure of other rodents to phthalates reduces testosterone synthesis during the fetal period $[15,65,66]$, leading to reproductive damage that persists up to adulthood [15,67]. However, Giribaru et al. [16] observed that rats exposed during gestation to the same DBP dose used here exhibited a decrease in serum testosterone levels in adulthood. Therefore, in comparison with other rodents, the gerbil appears to be less susceptible to DBP effects regarding the regulation of circulating testosterone, being the main impact in circulating and intratesticular estradiol levels. The aromatase enzyme is responsible for the conversion of testosterone and androstenedione to estradiol and estrone, respectively [68]. Thus, it is possible that gestational exposure to DBP may have induced the overexpression and increased aromatase enzyme activity by testicular cells, culminating in higher estradiol levels.

Comparing the hormonal changes of the gerbils exposed to DBP with offspring from mothers that ingested only corn oil, higher circulating estradiol levels were observed without alterations in intratesticular levels of this hormone. Pearlman [69] introduced the concept that the plasma level of a steroid was related to its production rate divided by its metabolism rate. This relationship is designated as the metabolic clearance rate [70], and it has proved to be a powerful tool in the study of steroid physiology. Higher estradiol serum levels in the $\mathrm{O}$ group may be due to alterations in the metabolic clearance rate, caused by reduction in hepatic metabolism of steroids, or damage in the mechanism of blood transport and cell entrance. It should be noted that, although the pregnant females were treated with a small amount of corn oil $(100 \mu \mathrm{l} /$ day), it corresponds to about $0.83 \mathrm{mg}$ of phytosterols, which can result in an effective physiological response in hormoneregulated organs, such as the liver and the reproductive organs. In conclusion, these data indicate that maternal corn oil alters the systemic metabolism of estradiol in adulthood.

\subsection{Testicular effects and sperm parameter alterations}

Studies have shown that exposure to phthalates, such as DBP and DEHP and their monoesters, increases the expression of PPAR in the testis, culminating in damage to the male reproductive system [71]. Ryu et al. [72] treated prepuberal rats at $750 \mathrm{mg} / \mathrm{kg} /$ day of DBP for 30 days and observed a significant increase in PPAR $\gamma$ levels in the testis. Testicular PPAR $\gamma$ content was unchanged in the gerbils showing that the present in utero exposure to DBP did not affect the expression of this receptor. We also found no alterations in the LXR $\alpha$, AR or ER $\alpha$ contents after DBP exposure. Increases in germ-cell apoptosis are often observed after exposing experimental animals to various testicular toxicants $[73,74]$. In this study, gestational exposure to DBP increased by about $48 \%$ the relative density of apoptotic cells in the testis. LXR $\alpha$ and $\operatorname{PPAR} \gamma$ had been implicated in increased rates of cell death. LXR $\alpha$-deficient mice present an increased apoptosis of the germ cells [75]. Ryu et al. [72] demonstrated that PPAR $\gamma$ might mediate DEHP-induced apoptosis in testicular cells. However, the increase in apoptosis in the 


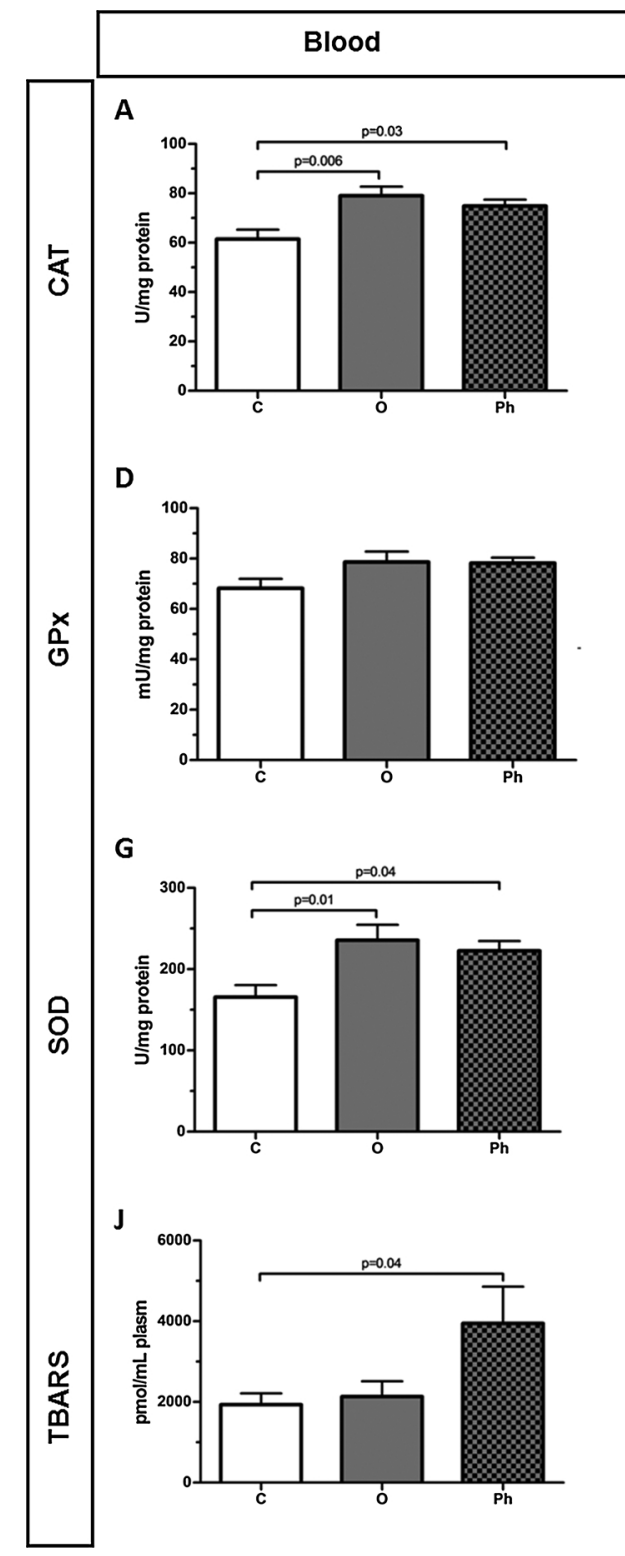

B

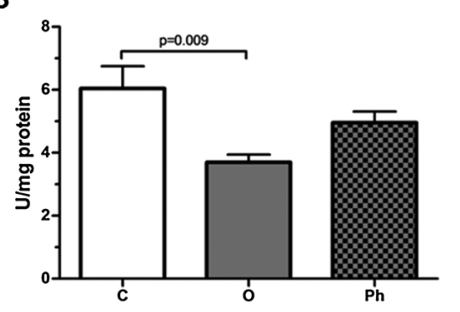

E

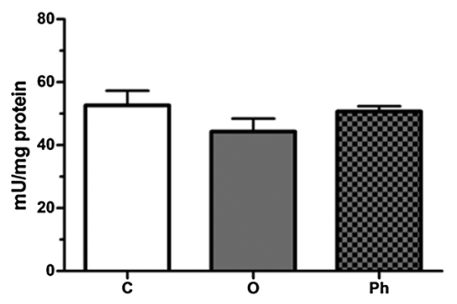

H

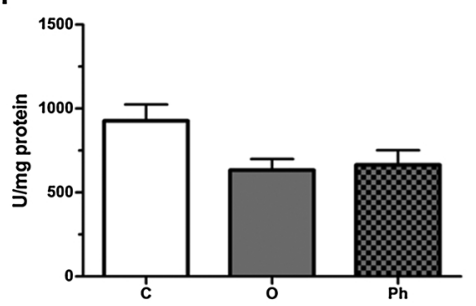

K

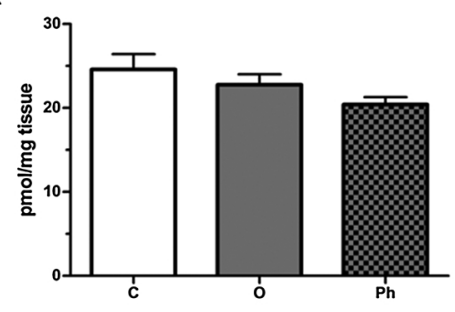

C

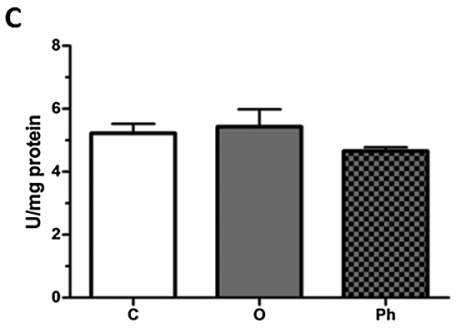

$\mathbf{F}$

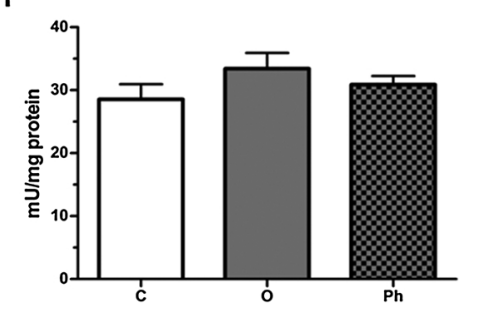

I

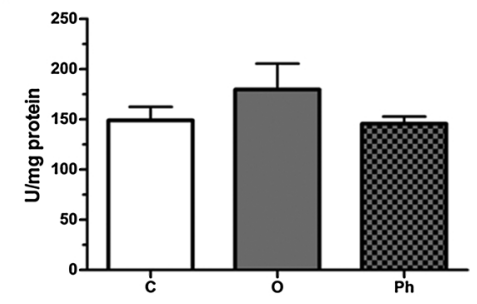

$\mathbf{L}$

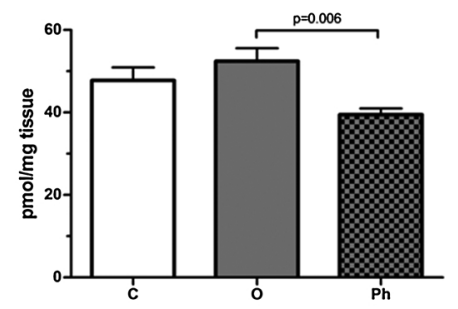

Fig. 7. Oxidative stress markers in blood samples and testicular and epidididmal fragments of gerbils from the Control (C), Oil (O) and Phthalate (Ph) groups. Antioxidant activity of the Catalase (CAT; A, B and C), Glutathione peroxidase (GPx; D, E and F) and Superoxide dismutase (SOD; G, H and I) enzymes was determined. Oxidized biomolecule levels were determined by thiobarbituric acid reactive substance (TBARS) assay (J, K and $\mathrm{L}$ ). $\mathrm{n}=7$ animals per group. Values are expressed as mean \pm SEM. Values $\mathrm{p}<0.05$ were considered significant (A, B, D, E, F, G, H, I, J and L. ANOVA test followed by Tukey's test; B and K. Kruskal-Wallis test followed by Dunn's test).

testis of the gerbils exposed to DBP was not related to alteration in PPAR $\gamma$ and LXR $\alpha$ expression. Higher intratesticular estradiol concentration may be responsible for apoptosis-induction in the testis [76].

Among other adverse effects of DBP exposure are decreases in the weight of the epididymis, testis and accessory sex glands [77-79]. Gerbils exposed to $100 \mathrm{mg} / \mathrm{kg} /$ day of DBP during gestation did not present alterations in testis and epididymis weights and in GSI, as well as other abnormalities in the reproductive system. DSP was unchanged either, but decreased sperm concentration in the epididymis and markedly impaired sperm motility. Considering that motility is one of the most important sperm parameters used for evaluation of semen quality $[80,81]$, we can conclude that high doses of DBP during pregnancy compromised sperm motility and the reproductive function of the gerbil. Giribabu et al. [16] verified that prenatal exposure to DBP alters the reproductive function of Wistar rats by reducing sperm concentration and motility.

The acquisition of sperm motility is dependent on the presence of androgens [82] and of an adequate process of sperm maturation in the epididymis [83,84]. Although estradiol is also essential for male fertility $[85,86]$, high estrogen levels are detrimental to epididymal function. A study by Goyal et al. [32] demonstrated that the administration of low doses ( $\geq 8 \mu \mathrm{g} /$ day) of DES, an estrogenic compound, to adult rats for 12 days reduced the epididymal weight and the sperm concentration in this organ, and impaired sperm motility without altering daily sperm production, providing relevant data for studying the role of estrogens in the function of the epididymis. In addition, regulation of the amount of cholesterol in the sperm plasma membrane during maturation is determinant for sperm motility [87]. Our data revealed no variations in circulating and intratesticular testosterone levels in the animals exposed to DBP, however serum and intratesticular levels of estradiol were higher in these animals, as well as total and non-HDL cholesterol and triglyceride levels, which may be improperly modulating the process of sperm maturation.

Regarding the reproductive alterations caused by the corn oil, we 
verified that gestational exposure to this plant oil increased the rate of seminiferous tubules presenting premature detachment of germ cell. Reame et al. [88] suggest, in their study of obesity induction in Wistar rats fed a high-fat diet, that the increase in the number of tubules with immature germ cell detachment was due to the reduction in serum testosterone levels. As already reported, these levels were unchanged in the animals exposed to corn oil, but we observed higher serum estradiol levels. In this group, a higher testicular expression of ERa was also observed, even without presenting higher intratesticular estradiol levels. It is known that spermatogenesis is dependent on steroid hormones, and alterations in testosterone and estradiol levels, especially high estrogen levels, result in impairments to male fertility [86-89]. The animals exposed to corn oil alone also presented a reduction in the sperm reserve and an increase in the rate of sperm without progressive movement. Moreover, the sperm transit time through the epididymis was reduced in this group. These results demonstrate that gestational exposure to corn oil also compromised the sperm quantity and quality and caused alterations in testicular histology and ER $\alpha$ content. Since these animals were found to have high levels of non-HDL cholesterol, the mechanisms involved in these reproductive disorders are probably related to the high levels of circulating cholesterol and estradiol.

One aspect that should be mentioned concerning the possible interferences of the maternal gavage in the metabolic and reproductive results detected to corn oil- treated group. Gavage is the most common technique for drug administration in pharmacokinetic and toxicological studies, with increasing number of researchers chosen this method [90]. However, up to date few studies have investigated, in a controlled manner, the level of stress induced by oral gavage per se and by restraint used to accomplish this procedure [39,91]. According to previous study with rats, in the present study the female gerbils of all groups to be subjected to gavage were manipulated daily for two weeks before gestation aiming to minimize the distressed associated to this procedure. Recently, McDonnell-Dowling et al. [90] also used the habituation to the technique to examine if oral gavage, as a route of drug administration, during pregnancy and lactation affected neurodevelopmental and behavioral outcomes in the offspring of rat dams. These authors concluded that daily oral gavage during gestation and lactation has no significant effect on rat dams. They also showed that gavage treatment of dams had no effect on developmental parameters in their offspring, including birth weight, pinna unfolding, fur appearance, anogenital distance, body weight, and neonatal death, concluding that oral gavage is a safe and feasible route of administration for use during pregnancy and lactation. So, we consider that the alterations detected in corn oiltreated group were caused by this plant oil and not as a result of gavage.

\subsection{Effects on oxidative stress markers}

Some effects of environmental contaminants are caused by the generation of reactive oxygen species (ROS) in both intra- and extracellular spaces of cells, leading to cell death and tissue injury [92,93]. Oxidative stress is known to be a major factor regulating the vitality and functionality of mammalian spermatozoa in vitro [94]. Sperm plasma membrane, being rich in polyunsaturated fatty acids, is highly susceptible to ROS attack and, consequently, to peroxidation of lipid bilayers [95]. Zhou et al. [95] revealed a dose-dependent epididymal toxicity of DBP, demonstrating that exposure to graded doses of DBP disrupts the epididymal structure and function by impacting the antioxidant enzyme activity (GPx and SOD) and increasing lipid peroxidation, thereby causing oxidative stress in the epididymis of the rats exposed to this phthalate $(500 \mathrm{mg} / \mathrm{kg} /$ day) for two weeks in adulthood. However, antioxidant enzyme activity and lipid peroxidation were unchanged at $100 \mathrm{mg} / \mathrm{kg} /$ day of DBP [33]. The marker most frequently used to indicate the level of lipid peroxidation or oxidized biomolecules is malondialdehyde (MDA) [96,97], which can be determined by many different techniques [98]. MDA can interfere in protein biosynthesis by forming adducts with DNA, RNA and protein [99]. Our data indicated that there was no change in CAT, GPx and SOD activities, and the levels of oxidized biomolecules were, unexpectedly, lower in the epididymis of the animals exposed to DBP during gestation. These results suggested that in utero exposure to $100 \mathrm{mg} / \mathrm{kg} /$ day of DBP was not a high enough dose to impact the mechanisms involved in oxidative stress regulation in this organ. Thus, it is probable that the sperm motility damage observed in this study was not caused by these mechanisms.

Data regarding the oxidative stress markers in the testis did not reveal any alterations in the antioxidant enzyme and TBARS levels of the animals in the $\mathrm{Ph}$ group. On the other hand, blood CAT and SOD activities were higher both in animals exposed to DBP and in animals exposed to corn oil, while plasmatic TBARS levels increased only in those gerbils exposed to DBP. These data show that gestational exposure to $100 \mathrm{mg} / \mathrm{kg} /$ day of DBP augmented oxidative stress in the blood, even with the increase of the antioxidant response observed. The results confirm the importance of blood evaluation, which acts in the protection of lesions in the organs and also reflects the systemic condition of the organism.

A particularly relevant finding of this study concerns the use of corn oil as a vehicle. As verified throughout the study, most of the effects of gestational exposure to DBP are observed when compared to the control group. Corn oil is one of the major diluent vehicles of liposoluble substances to be administered in animal models orally $[4,11,16,32,33,77]$. Our results indicate that daily intake of corn oil by pregnant females can cause metabolic alterations in the offspring. In addition, it can result in damage to steroidogenesis, altering the profile of sexual steroids, and compromise semen quantity and quality. As mentioned above, changes in sperm parameters were not due to the reduction in DSP, but probably as a result of problems in epididymal function. These data indicate that the use of this agent as a vehicle for the administration of oral substances is not adequate in studies on the reproductive system or metabolic parameters. This is a cause for concern, which needs a lot of attention and better investigation, since the real effects of the drug tested may be being camouflaged by corn oil.

\section{Conclusion}

In conclusion, maternal intake of corn oil, a widely used diluent vehicle, led to alterations in the lipid metabolism and circulating estradiol levels, increasing testicular ER $\alpha$ expression and reducing sperm quantity and quality of the gerbil in adulthood. Our results also indicate that gestational exposure to DBP causes perturbations in the lipid metabolism and in the intratesticular synthesis of estradiol of the gerbil, with resulting damage to the sperm parameters. These findings provide important data about DBP exposure in other mammalian species, and point to an important issue regarding the use of corn oil as a diluent vehicle.

\section{Funding}

This work was supported by São Paulo State Research Foundation FAPESP [Grant to Rejane Maira Góes: 2013/16368-7, and doctoral fellowship to Ana Carolina Negrin: 2014/04146-2] and by National Counsel of Technological and Scientific Development - CNPq [Grant to Rejane Maira Góes: 308367/2014-6].

\section{Conflicts of interest}

The authors declare no conflicts of interest

\section{Acknowledgements}

The authors are gratefully to Mr Luiz Roberto Faleiros Júnior for the technical assistance, and to Prof Peter James Harris for the Englishlanguage revision of this paper. 


\section{References}

[1] World Health Organization - WHO, Global Assessment of the State-of-the-science of Endocrine Disruptors, (2002) (accessed 8 February 2018), http://www.who.int/ ipcs/publications/new_issues/endocrine_disruptors/en/.

[2] S. Pflieger-Bruss, H.C. Schuppe, W.B. Schill, The male reproductive system and its susceptibility to endocrine disrupting chemicals, Andrologia 36 (6) (2004) 337-345, https://doi.org/10.1111/j.1439-0272.2004.00641.x.

[3] R.R. Newbold, E. Padilla-Banks, R.J. Snyder, T.M. Phillips, W.N. Jefferson, Developmental exposure to endocrine disruptors and the obesity epidemic, Reprod. Toxicol. 23 (3) (2007) 290-296, https://doi.org/10.1016/j.reprotox.2006.12.010.

[4] D.J. Macleod, R.M. Sharpe, M. Welsh, M. Fisken, H.M. Scott, G.R. Hutchison, et al., Androgen action in the masculinization programming window and development of male reproductive organs, Int. J. Androl. 33 (2010) 279-287, https://doi.org/10. 1111/j.1365-2605.2009.01005.x.

[5] J. Stel, J. Legler, The role of epigenetics in the latent effects of early life exposure to obesogenic endocrine disrupting chemicals, Endocrinology 156 (10) (2015) 3466-3472, https://doi.org/10.1210/en.2015-1434.

[6] B.C. Blount, M.J. Silva, S.P. Caudill, L.L. Needham, J.L. Pirkle, E.J. Sampson, et al., Levels of seven urinary phthalate metabolites in a human reference population, Eviron Health Perspect 108 (10) (2000) 970-982.

[7] E. Mylchreest, D.G. Wallace, R.C. Cattley, P.M.D. Foster, Dose-dependent alterations in androgen-regulated male reproductive development in rats exposed to di(nbutyl) phthalate during late gestation, Toxicol. Sci. 55 (1) (2000) 143-151, https:// doi.org/10.1093/toxsci/55.1.143.

[8] W.W. Huber, B. Grasl-Kraupp, R. Schulte-Hermann, Hepatocarcinogenic potential of di(2-ethylhexyl)phthalate in rodents and its implications on human risk, Crit. Rev. Toxicol. 26 (4) (1996) 365-481, https://doi.org/10.3109/ 10408449609048302.

[9] J.A. Thomas, M.J. Thomas, Biological effects of di-(2-ethyl-hexyl) phthalate and other phthalic acid esters, Crit. Rev. Toxicol. 13 (1984) 283-317, https://doi.org/ 10.3109/10408448409023761.

[10] E. Mylchreest, M. Sar, R.C. Cattley, P.M. Foster, Disruption of androgen-regulated male reproductive development by di(n-butyl) phthalate during late gestation in rats is different from flutamide, Toxicol. Appl. Pharmacol. 156 (2) (1999) 81-95, https://doi.org/10.1006/taap.1999.8643.

[11] C.M. Carruthers, P.M.D. Foster, Critical window of male reproductive tract development in rats following gestational exposure to di-n-butyl phthalate, Birth Defects Res. B Dev. Reprod. Toxicol. 74 (3) (2005) 277-285, https://doi.org/10.1002/bdrb. 20050.

[12] W.R. Scarano, F.C. Toledo, M.T. Guerra, P.F.F. Pinheiro, R.F. Domeniconi, S.L. Felisbino, et al., Functional and morphological reproductive aspects in male rats exposed to di-n-butyl phthalate (DBP) in utero and during lactation, J. Toxicol. Environ. Health 73 (2010) 972-984, https://doi.org/10.1080/ 15287391003751760.

[13] R.N. Wine, L.H. Li, L.H. Barnes, D.K. Gulati, R.E. Chapin, Reproductive toxicity of di-n-butyl phthalate in a continuous breeding protocol in Sprague-Dawley rats, Environ. Health Perspect. 105 (1) (1997) 102-107, https://doi.org/10.1289/ehp. 97105102.

[14] Y. Zhang, X. Jiang, B. Chen, Reproductive and developmental toxicity in F1 Sprague- Dawley male rats exposed to di-n-butyl phthalate in utero and during lactation and determination of its NOAEL, Reprod. Toxicol. 18 (5) (2004) 669-676, https://doi.org/10.1016/j.reprotox.2004.04.009.

[15] L.G. Parks, J.S. Ostby, C.R. Lambright, B.D. Abbott, G.R. Klinefelter, N.J. Barlow, L.E. Gray, The plasticizer dietylhexyl phthalate induces malformations by decreasing fetal testosterone synthesis during sexual differentiation in the male rat Toxicol. Sci. 58 (2) (2000) 339-349, https://doi.org/10.1093/toxsci/58.2.339.

[16] N. Giribabu, S.B. Sainath, P.S. Reddy, Prenatal di-n-butyl phthalate exposure alters reproductive functions at adulthood in male rats, Environ. Toxicol. 29 (5) (2012) 534-544, https://doi.org/10.1002/tox.21779.

[17] M. Ema, Antiandrogenic effects of dibutyl phthalate and its metabolite, monobutyl phthalate, in rats, Congenit. Anom. 42 (4) (2002) 297-308, https://doi.org/10 1111/j.1741-4520.2002.tb00896.x.

[18] S. Jobling, T. Reynolds, R. White, M.G. Parker, J.P. Sumpter, A variety of environmentally persistent chemicals, including some phthalate plasticizers, are weakly estrogenic, Environ. Health Perspect. 103 (6) (1995) 582-587, https://doi. org/10.2307/3432434

[19] E. Filipiak, R. Walczak-Jedrzejowska, M. Krupinski, E. Oszukowsha, K. Marchlewska, J. Dlugonski, et al., Di(n-butyl) phthalate has no effect on the rat prepubertal testis despite its estrogenic activity in vitro, Folia Histochem. Cytobiol. 49 (4) (2011) 685-689, https://doi.org/10.5603/FHC.2011.0092.

[20] K.W. Gaido, J.B. Hensley, D.G. Wallace, S. Borghoff, K.J. Johnson, S.J. Hall, K. Boekelheide, Fetal mouse phthalate exposure shows that gonocyte multinucleation is not associated with decreased testicular testosterone, Toxicol. Sci. 97 (2) (2007) 491-503, https://doi.org/10.1093/toxsci/kfm049.

[21] A. Lehraiki, C. Racine, A. Krust, R. Habert, C. Levacher, Phthalates impair germ cell number in the mouse fetal testis by an androgen- and estrogen-independent mechanism, Toxicol. Sci. 111 (2) (2009) 372-382, https://doi.org/10.1093/toxsci/ kfp153.

[22] V. Muczynsky, J.P. Cravedi, A. Lehraiki, D. Moisin, C. Lecureuil, S. Messiaen, et al., Effects of mono-(2-ethylhexyl) phthalate on human and mouse fetal testis: in vitro and in vivo approaches, Toxicol. Appl. Pharmacol. 261 (1) (2012) 97-104, https:// doi.org/10.1016/j.taap.2012.03.016.

[23] D.G. Robinson, The anatomy of the Mongolian gerbil, Publishe's Foreword, USA (1974).
[24] M.M. de Jesus, A.C. Negrin, S.R. Taboga, M.E. Pinto-Fochi, R.M. Góes, Histopathological alterations in the prostates of Mongolian gerbils exposed to a high-fat diet and di-n-butyl phthalate individually or in combination, Reprod. Toxicol. 52 (2015) 26-39, https://doi.org/10.1016/j.reprotox.2015.02.005.

[25] J.Q. Antoniassi, R.A. Fochi, R.M. Góes, P.S.L. Vilamaior, S.R. Taboga, Corticosterone influences gerbil (Meriones unguiculatus) prostatic morphophysiology and alters its proliferation and apoptosis rates, Int. J. Exp. Pathol. 98 (3) (2017) 134-146, https://doi.org/10.1111/iep.12232.

[26] S.J. Colleta, J.Q. Antoniassi, M. Zanatelli, F.C. Santos, R.M. Góes, P.S. Vilamaior, S.R. Taboga, Acute exposure to bisphenol A and cadmium causes changes in the morphology of gerbil ventral prostates and promotes alterations in androgen-dependent proliferation and cell death, Environ. Toxicol. 32 (1) (2017) 48-61, https://doi.org/10.1002/tox.22211.

[27] A.P. Perez, M.F. Biancardi, C.R. Caires, L.R. Falleiros, Jr, R.M. Góes, F.C. Santos, S.R. Taboga, Pubertal exposure to ethinylestradiol promotes different effects on the morphology of the prostate of the male and female gerbil during aging, Environ. Toxicol. 32 (2) (2017) 477-489, https://doi.org/10.1002/tox.22252.

[28] C.H. Facina, S.G.P. Campos, B.F. Gonçalves, R.M. Góes, P.S.L. Vilamaior, S.R. Taboga, Long-term oral exposure to safe dose of bisphenol A in association with high-fat diet stimulate the prostatic lesions in a rodent model for prostate cancer, Prostate 78 (2) (2018) 152-163, https://doi.org/10.1002/pros.23458.

[29] F. Grün, B. Blumberg, Environmental obesogens: organotins and endocrine disruption via nuclear receptor signaling, Endocrinology 147 (2006) 50-55, https:// doi.org/10.1210/en.2005-1129.

[30] C. Lubrano, G. Genovesi, P. Specchia, D. Costantini, S. Mariani, E. Petrangeli, et al., Obesity and metabolic comorbidities: environmental diseases? Oxid. Med. Cell. Longev. (2013) 640673, https://doi.org/10.1155/2013/640673.

[31] H.Z. Ying, C. Yu, Z. Wang, B. Yu, J.N. Zang, Y. Liu, Characterization and mechanisms of lipid metabolism in high-fat diet induced hyperlipidemia in Mongolian gerbil (Meriones unguiculatus), Afr. J. Biotechnol. 11 (97) (2012) 16347-16352, https://doi.org/10.5897/AJB12.336.

[32] H.O. Goyal, T.D. Braden, M. Mansour, C.S. Willians, A. Kamaleldin, K.K. Srisvastava, Diethylstilbestrol-treated adult rats with altered epididymal sperm numbers and sperm motility parameters, but without alterations in sperm production and sperm morphology, Biol. Reprod. 64 (3) (2001) 927-934, https://doi.org/ 10.1095/biolreprod64.3.927.

[33] D. Zhou, H. Wang, J. Zhang, Di-n-butyl phthalate (DBP) exposure induces oxidative stress in epididymis of adult rats, Toxicol. Ind. Health 27 (1) (2011) 65-71, https:// doi.org/10.1177/0748233710381895.

[34] J.N. Rodrigues, L.A. Gioielle, C. Anton, Chemical interesterification of milkfat and milkfat-corn oil blends, Food Res. Int. 36 (2003) 149-159, https://doi.org/10. 1016/S0963-9969(02)00130-8.

[35] Ostlund REJr, S.B. Racette, A. Okeke, W.F. Stenson, Phytosterols that are naturally present in commercial corn oil significantly reduce cholesterol absorption in humans, Am. J. Clin. Nutr. 75 (6) (2002) 1000-1004.

[36] J.H. Marston, M.C. Chang, The breeding, management and reproductive physiology of the Mongolian gerbil (Meriones unguiculatus), Lab. Anim. Care 15 (1965) 34-48.

[37] M.E. Pinto-Fochi, A.C. Negrin, W.R. Scarano, S.R. Taboga, R.M. Góes, Sperm parameters and sexual maturation of Mongolian gerbil (Meriones unguiculatus), Reprod. Fertil. Dev. 28 (6) (2016) 815-823, https://doi.org/10.1071/RD14074.

[38] M.L. Norris, C.E. Adams, Mating post-partum and length of gestation in the Mongolian gerbil (Meriones unguiculatus), Lab. Anim. 15 (2) (1981) 189-191, https://doi.org/10.1258/002367781780958883.

[39] P.V. Turner, E. Vaughn, J. Sunohara-Neilson, J. Ovari, F. Leri, Oral gavage in rats: animal welfare evaluation, J. Am. Assoc. Lab. Anim. Sci. 51 (1) (2012) 25-30.

[40] B.A. Taylor, S.J. Phillips, Detection of obesity QTLs on mouse chromosomes 1 and 7 by selective DNA pooling, Genomics 34 (3) (1996) 389-398, https://doi.org/10. 1006/geno.1996.0302.

[41] X. Fan, E.Y. Liu, V.P. Hoffman, A.J. Potts, B. Sharma, D.C. Henderson, Triglyceride/ high-density lipoprotein cholesterol ratio: a surrogate to predict insulin resistance and low-density lipoprotein cholesterol particle size in nondiabetic patients with schizophrenia, J. Clin. Psychiatry 72 (6) (2011) 806-812, https://doi.org/10.4088/ JCP.09m05107yel.

[42] T.M. Segatelli, L.R. França, P.F.F. Pinheiro, C.C.D. Almeida, M. Martinez, F.E. Martinez, Spermatogenic cycle length and spermatogenic efficiency in the gerbil (Meriones unguiculatus), J. Androl. 25 (6) (2004) 872-880, https://doi.org/ 10.1002/j.1939-4640.2004.tb03156.x.

[43] G.W. Robb, R.P. Amann, G.J. Killian, Daily sperm production and epididymal sperm reserves of pubertal and adult rats, J. Reprod. Fertil. 54 (1) (1978) 103-117, https://doi.org/10.1530/jrf.0.0540103.

[44] G.S. Fernandes, A.C. Arena, C.D.B. Fernandez, A. Mercadante, L.F. Barbisan, W.G. Kempinas, Reproductive effects in male rats exposed to diuron, Reprod. Toxicol. 23 (1) (2007) 106-112, https://doi.org/10.1016/j.reprotox.2006.09.002.

[45] W.E. Berndtson, Methods for quantifying mammalian spermatogenesis: a review, J. Anim. Sci. 44 (1977) 818-833.

[46] L. Johnson, D.D. Varner, M.E. Roberts, T.L. Smith, G.E. Keillor, W.L. Scrutchfield, Efficiency of spermatogenesis: a comparative approach, Anim. Reprod. Sci. 60-61 (2000), https://doi.org/10.1016/S0378-4320(00)00108-1 471-80.

[47] R.P. Amann, J.F. Kavanaugh, L.C. Griel, Jr, J.K. Voglmayr, Sperm production of holstein bulls determined from testicular spermatid reserves, after cannulation of rete testis or vas deferens, and by daily ejaculation, J. Dairy Sci. 57 (1) (1976) 93-99, https://doi.org/10.3168/jds.S0022-0302(74)84836-8.

[48] J.E. Perobelli, M.F. Martinez, C.A.S. Franchi, C.D.B. Fernandez, J.V. Camargo, W.G. Kempinas, Decreased sperm motility in rats orally exposed to single or mixed pesticides, J. Toxicol. Environ Health A 73 (13-14) (2010), https://doi.org/10. $1080 / 15287391003751802$ 991-1002 
[49] M.M. Bradford, A rapid and sensitive method for the quantitation of microgram quantities of protein utilizing the principle of protein-dye binding, Anal. Biochem. 72 (1976) 248-254, https://doi.org/10.1016/0003-2697(76)90527-3.

[50] M.E. Pinto-Fochi, E.Z. Pytlowanciv, V. Reame, A. Rafacho, D.L. Ribeiro, S.R. Taboga, R.M. Góes, A high-fat diet fed during different periods of life impairs steroidogenesis of rat Leydig cells, Reproduction 152 (6) (2016) 795-808, https:// doi.org/10.1530/REP-16-0072.

[51] E. Beutler, Red cell metabolism: a manual of biochemical methods, Yale J. Biol. Med. (1975) Grune and Straton; New York.

[52] H. Sies, O.R. Koch, E. Martino, A. Boveris, Increased biliary glutathione disulfide release in chronically ethanol treated rats, FEBS Lett. 103 (2) (1979) 287-290, https://doi.org/10.1016/0014-5793(79)81346-0.

[53] H.J. Forman, O. Augusto, R. Brigelius-Flohe, P.A. Dennery, B. Kalyanaraman, $\mathrm{H}$. Ischiropoulos, et al., Even free radicals should follow some rules: a guide to free radical research terminology and methodology, Free Radic. Biol. Med. 78 (2015) 233-235, https://doi.org/10.1016/j.freeradbiomed.2014.10.504.

[54] M. Uchiyama, M. Mihara, Determination of malonaldehyde precursor in tissues by thiobarbituric acid test, Anal. Biochem. 86 (1) (1978) 271-278, https://doi.org/10. 1016/0003-2697(78)90342-1.

[55] C. Li, H. Guo, F. Dai, X. Huo, Z. Li, S. Zhang, et al., SREBP-2 expression pattern contributes to susceptibility of Mongolian gerbils to hypercholesterolemia, Mol. Med. Rep. 17 (2) (2018) 3288-3296, https://doi.org/10.3892/mmr.2017.8195.

[56] T. Ramjiganesh, S. Roy, H.C. Freake, J.C. Mcintyre, M.L. Fernandez, Corn fiber oil lowers plasma cholesterol by altering hepatic cholesterol metabolism and up-regulating LDL receptors in guinea pigs, J. Nutr. 132 (3) (2002) 335-340, https://doi org/10.1093/jn/132.3.335.

[57] K.C. Maiki, A.L. Lawless, K.M. Kelley, V.N. Kaden, C.J. Geiger, M.R. Dicklin, Corn oil improves the plasma lipoprotein lipid profile compared with extra-virgin olive oil consumption in men and women with elevated cholesterol: results from a randomized controlled feeding trial, J. Clin. Lipidol. 9 (1) (2015) 49-57, https://doi. org/10.1016/j.jacl.2014.10.006.

[58] E. Poveda, P. Ayala, M. Rodriguez, E. Ordóñez, C. Baracaldo, W. Delgado, M. Guerra, Efecto del suplemento de aceites vegetales sobre el perfil lipídico em ratas Wistar, Biomedica 25 (1) (2005) 101-109, https://doi.org/10.7705/issn. 0120-4157.

[59] W.T. Schaiff, F.F. Knapp, Jr, Y. Barak, T. Biron-Shental, D.M. Nelson, Y. Sadovsky, Ligand-activated peroxisome proliferator activated receptor gamma alters placental morphology and placental fatty acid uptake in mice, Endocrinology 148 (8) (2007) 3625-3634, https://doi.org/10.1210/en.2007-0211.

[60] S.A. Segovia, M.H. Vickers, C. Gray, C.M. Reynolds, Maternal obesity, inflammation and developmental programming, Biomed Res. Int. 418975 (2014), https://doi. org/10.1155/2014/418975 2014

[61] B.M. Gregorio, V. Souza-Mello, J.J. Carvalho, C.A. Mandarim-de-Lacerda, M.B. Aguila, Maternal high-fat intake predisposes nonalcoholic fatty liver disease in C57BL/6 offspring, Am. J. Obstet. Gynecol. 203 (5) (2010) 495, https://doi.org/10. 1016/j.ajog.2010.06.042 e1-4958.

[62] G. Chinetti, J.C. Fruchat, B. Staels, Peroxisome proliferator-activated receptors (PPARs): nuclear receptors at the crossroads between lipid metabolism and inflammation, Inflamm. Res. 49 (2000) 497-505, https://doi.org/10.1007/ s000110050622.

[63] R.R. Newbold, Impact of environmental endocrine disrupting chemicals on the development of obesity, Hormones 9 (2010) 206-217.

[64] A. Pereira-Fernandes, H. Demaegdt, K. Vandermeiren, T.L.M. Hectors, P.G. Jorens, R. Blust, et al., Evaluation of a screening system for obesogenic compounds: screening of endocrine disrupting compounds and evaluating of the PPAR dependency of the effects, PLoS ONE 8 (10) (2013) e77481, https://doi.org/10.1371/ journal.pone.0077481.

[65] K.P. Lehmann, S. Phillips, M. Sar, P.M. Foster, K.W. Gaido, Dose-dependent alterations in gene expression and testosterone synthesis in the fetal testes of male rats exposed to di (n-butyl) phthalate, Toxicol. Sci. 81 (1) (2004) 60-68, https:// doi.org/10.1093/toxsci/kfh169.

[66] A.C. Lourenço, C. Gomes, A.C. Boareto, R.P. Mueller, F. Nihi, L.F. Andrade, et al Influence of oily vehicles on fetal testis and lipid profile of rats exposed to di-butyl phthalate, Hum. Exp. Toxicol. 33 (1) (2014) 54-63, https://doi.org/10.1177/ 0960327112474847.

[67] I.K. Mahood, H.M. Scott, R. Brown, N. Hallmark, M. Walker, R.M. Sharpe, In utero exposure to di(n-butyl) phthalate and testicular dysgenesis: comparison of fetal and adult end points and their dose sensitivity, Environ. Health Perspect. 115 (1) (2007) 55-61, https://doi.org/10.1289/ehp.9366.

[68] A.M. Brodie, Aromatase inhibition and its pharmacologic implications, Biochem. Pharmacol. 34 (1985) 3213-3219.

[69] W.H. Pearlman, [16-3H] Progesterone metabolism in advanced pregnancy and in oophorectomized-hysterectomized women, Biochem. J. 67 (1) (1957).

[70] J.F. Tait, Review: the use of isotopic steroids for the measurement of production rates in vivo, J. Clin. Endocrinol. 23 (1963) 1285.

[71] J.C. Corton, P.J. Lampinskas, Peroxisome proliferator-activated receptors: mediators of phthalate ester-induced effects in the male reproductive tract? Toxicol. Sci. 83 (1) (2005) 4-17, https://doi.org/10.1093/toxsci/kfi011.

[72] J.Y. Ryu, B.M. Lee, S. Kacew, H.S. Kim, Identification of differentially expressed genes in the testis of Sprague-Dawley rats treated with di(n-butyl) phthalate, Toxicol 234 (2007) 103-122, https://doi.org/10.1016/j.tox.2007.02.003.

[73] C. Strandgaard, M.G. Miller, Germ cell apoptosis in rat testis after administration of 1,3-dinitrobenzene, Reprod Toxicol. 12 (2) (1998) 97-103.

[74] J.H. Richburg, A. Nañes, Fas- or FasL-deficient mice display an increased sensitivity to nitrobenzene-induced testicular germ cell apoptosis, Toxicol. Lett. 139 (1) (2003) 1-10, https://doi.org/10.1016/S0378-4274(02)00419-8.

[75] D.H. Volle, K. Mouzat, R. Duggavathi, B. Siddeek, P. Déchelotte, B. Sion, et al., Multiple roles of the nuclear receptors for oxysterols liver $\mathrm{X}$ receptor to maintain male fertility, Mol. Endocrinol. 21 (5) (2007) 1014-1027, https://doi.org/10.1210/ me.2006-0277.

[76] J. Blanco-Rodríguez, C. Martínez-García, Induction of apoptotic cell death in the seminiferous tubule of the adult rat testis: assessment of the germ cell types that exhibit the ability to enter apoptosis after hormone suppression by oestradiol treatment, Int. J. Androl. 19 (4) (1996) 237-247, https://doi.org/10.1111/j.1365 2605.1996.tb00468.x.

[77] R.W. Moore, T.A. Rudy, T. Lin, K. Ko, R.E. Peterson, Abnormalities of sexual development in male rats with in utero and lactational exposure to the antiandrogenic plasticizer di(2-ethylhexyl) phthalate, Environ. Health Perspect. 109 (3) (2001) 229-237, https://doi.org/10.1289/ehp.01109229.

[78] J.S. Fisher, Environmental anti-androgens and male reproductive health: focus on phthalates and testicular dysgenesis syndrome, Reproduction 127 (2004) 305-315, https://doi.org/10.1530/rep.1.00025.

[79] S. Moody, H. Goh, A. Bielanowicz, P. Rippom, K.L. Loveland, C. Itman, Prepubera mouse testis growth and maturation and androgen production are acutely sensitive to di-n-butyl phthalate, Endocrinology 154 (2013) 3460-3475, https://doi.org/10 1210/en.2012-2227.

[80] D.E. Brooks, Epididymal functions and their hormonal regulation, Aust. J. Biol. Sci. 36 (3) (1983) 205-221.

[81] R. Sullivan, F. Saez, J. Girouard, G. Frenette, Role of exosomes in sperm maturation during the transit along the male reproductive tract, Blood Cells Mol. Dis. 35 (1) (2005) 1-10, https://doi.org/10.1016/j.bcmd.2005.03.005.

[82] M.C. Orgebin-Crist, P.L. Tichenor, Effect of testosterone on sperm maturation in vitro, Nature 245 (1973) 328-329, https://doi.org/10.1038/245328a0.

[83] G.A. Cornwall, New insights into epididymal biology and function, Hum. Reprod. Update 15 (2) (2009) 213-227, https://doi.org/10.1093/humupd/dmn055.

[84] A.S. Raymond, B. Elder, M. Ensslin, B.D. Shur, Loss of SED1/MFG-E8 results in altered luminal physiology in the epididymis, Mol. Reprod. Dev. 77 (6) (2010) 550-563, https://doi.org/10.1002/mrd.21189.

[85] D.B. Lubahn, J.S. Moyer, T.S. Golding, J.F. Couse, K.S. Korach, O. Smithies, Alteration of reproductive function but not prenatal sexual development after insertional disruption of the mouse estrogen receptor gene, Proc. Natl. Acad. Sci. 90 (23) (1993) 11162-11166, https://doi.org/10.1073/pnas.90.23.11162.

[86] S. Carreau, C. Bois, L. Zanatta, F.R. Silva, H. Bouraima-Lelong, C. Delalande, Estrogen signaling in testicular cells, Life Sci. 89 (2011) 15-16, https://doi.org/10 1016/j.lfs.2011.06.004 584-587.

[87] T. Leahy, B.M. Gadella, New insights into the regulation of cholesterol efflux from the sperm membrane, Asian J. Androl. 17 (2015) 561-567, https://doi.org/10. 4103/1008-682X.153309.

[88] V. Reame, E.Z. Pytlowanciv, D.L. Ribeiro, T.F. Pissolato, S.R. Taboga, R.M. Góes, M.E. Pinto-Fochi, Obesogenic environment by excess of dietary fats in different phases of development reduces spermatic efficiency of Wistar rats at adulthood: correlations with metabolic status, Biol. Reprod. 91 (6) (2014) 1-10, https://doi. org/10.1095/biolreprod.114.121962 151

[89] X. Li, N. Rahman, Impact of androgen/estrogen ratio: lessons learned from the aromatase over-expression mice, Gen. Comp. Endocrinol. 159 (1) (2008) 1-9, https://doi.org/10.1016/j.ygcen.2008.07.025.

[90] K. McDonnell-Dowling, S. Kleefeld, J.P. Kelly, Consequences of oral gavage during gestation and lactation on rat dams and the neurodevelopment and behavior of their offspring, J. Am. Assoc. Lab. Anim. Sci. 56 (1) (2017) 79-83.

[91] M. Bonnichsen, N. Dragsted, A.K. Hansen, The welfare impact of gavaging laboratory rats, Anim. Welf. 14 (3) (2005) 223-227.

[92] A. Arif, H. Ahmad Khan, Environmental toxins and Parkinson's disease: putative roles of impaired electron transport chain and oxidative stress, Toxicol. Ind. Health 26 (2) (2010) 121-128, https://doi.org/10.1177/0748233710362382.

[93] H.A. Aly, O. Domènech, A.B. Abdel-Naim, Aroclor 1254 impairs spermatogenesis and induces oxidative stress in rat testicular mitochondria, Food Chem. Toxicol. 47 (8) (2009) 1733-1738, https://doi.org/10.1016/j.fct.2009.03.019.

[94] R.J. Aitken, B.J. Curry, Redox regulation of human sperm function: from the physiological control of sperm capacitation to the etiology of infertility and DNA damage in the germ line, Antioxid. Redox Signal. 14 (2011) 367-381, https://doi.org/ 10.1089/ars.2010.31861.

[95] D. Zhou, H. Wang, J. Zhang, X. Gao, W. Zhao, Y. Zheng, Di-n-butyl phthalate (DBP) exposure induces oxidative damage in testes of adult rats, Syst. Biol. Reprod. Med. 56 (6) (2010) 413-419, https://doi.org/10.3109/19396368.2010.509902.

[96] H. Esterbauer, R.J. Schaur, H. Zollner, Chemistry and biochemistry of 4-hydroxynonenal, malonaldehyde and related aldehydes, Free Radic. Biol. Med. 11 (1) (1991) 81-128, https://doi.org/10.1016/0891-5849(91)90192-6.

[97] D. Grotto, L. Santa Maria, J. Valentini, C. Paniz, G. Schimtt, S.C. Garcia, et al., Importance of the lipid peroxidation biomarkers and methodological aspects for malondialdehyde quantification, Quím Nova 32 (2009) 169-174, https://doi.org/ 10.1590/S0100-40422009000100032.

[98] A.L. Spirlandeli, R. Deminice, A.A. Jordao, Plasma malondialdehyde as biomarker of lipid peroxidation: effects of acute exercise, Int. J. Sports Med. 35 (1) (2014) 14-18, https://doi.org/10.1055/s-0033-1345132.

[99] K. Doreswamy, B. Shrilatha, T. Rajeshkumas, Muralidhara, Nickel-induced oxidative stress in testes of mice: evidence of DNA damage and genotoxic effects, J. Androl. 25 (2004) 996-1003, https://doi.org/10.1002/j.1939-4640.2004. tb03173.x. 